\title{
Applying ex-post index decomposition analysis to primary energy consumption for evaluating progress towards European energy efficiency targets
}

\author{
Matthias Reuter • Martin K. Patel • \\ Wolfgang Eichhammer
}

Received: 19 September 2016 / Accepted: 28 April 2017 / Published online: 11 May 2017

(C) The Author(s) 2017. This article is an open access publication

\begin{abstract}
Monitoring the progress of the European Union and its Member States towards the EU's energy efficiency target is a crucial part of the mandatory process as defined in the Energy Efficiency Directive 2012/27/EU. In this paper, we conduct index decomposition analyses to show the effects of both policies and autonomous developments driving the changes of primary energy consumption for the European Union (EU28) and its Member States for the time period of 2000 to 2014, with a comparative analysis of Germany and Poland. These analyses are based on the logarithmic mean Divisia index methodology and primarily on data compiled by Eurostat. They are carried out on two levels, i.e. on the level of total primary energy consumption as well as on the level of primary energy consumption related to electricity generation. The first level examines the influences of changes in final energy consumption and changes within the energy conversion sector on primary energy consumption. With the second level, we provide insights into the effects of changes in electricity consumption and production. According to
\end{abstract}

M. Reuter $(\bowtie) \cdot$ W. Eichhammer

Fraunhofer Institute for Systems and Innovation Research (ISI), Breslauer Straße 48, 76139 Karlsruhe, Germany

e-mail: matthias.reuter@ isi.fraunhofer.de

M. K. Patel

Department F.-A. Forel for Environmental and Aquatic Sciences, University of Geneva, Boulevard Carl-Vogt 66, 1205 Genève, Switzerland

W. Eichhammer

Copernicus Institute of Sustainable Development, Utrecht University, Heidelberglaan 2, 3584 CS Utrecht, The Netherlands our first-level analysis, the consumption of primary energy in the EU28 is primarily influenced by an increased share of electrical energy and the counteracting effect of rising efficiency in electricity generation, induced by an increasing share of renewable energies. Furthermore, the reduction of final energy consumption had a significant decreasing influence on primary energy consumption in the European Union. The second level of our analysis regarding electricity generation shows that the increasing effect on primary energy consumption due to the rising consumption of electricity was mainly compensated by substituting nuclear and thermal power plants by renewable energy technologies.

Keywords Energy efficiency targets · Primary energy · Decomposition analysis · Policy evaluation · European Union · Germany · Poland

\section{Introduction}

As part of the so-called 20-20-20 targets (European Council 2009), the European Union has set itself the target to reduce energy consumption by $20 \%$ compared to a baseline. The other two goals are a share of $20 \%$ renewables in final energy consumption by 2020 and a $20 \%$ reduction of greenhouse gas emissions in 2020 compared to 1990 . This target "triad" has recently been extended until 2030 and it now includes (European Council 2014) at least $40 \%$ cuts in greenhouse gas emissions (from 1990 levels), a share of at least $27 \%$ renewable energy and at least $27 \%$ improvement in 
energy efficiency. The proposal for an amendment of the Energy Efficiency Directive (EED) sets a 30\% binding energy efficiency target for 2030 at EU level (European Commission 2016b).

These targets are not independent of each other: for example, the penetration of renewables in the power generation sector has impacts on primary energy consumption, hence on the fulfilment of the energy efficiency target. This is due to the following effect: While the physical energy efficiency of renewable energy technologies is below $100 \%$ (e.g. up to around $20 \%$ for multicrystalline photovoltaic cells and up to around $50 \%$ for wind energy), international energy balances as published by the International Energy Agency (IEA) apply the so-called physical energy content method (IEA 2016). According to this method, the first energy form used downstream in the conversion process is defined as primary energy (in contrast to both the "substitution method" and the "direct equivalent method"; see Edenhofer et al. 2012, p. 180). Renewable energy technologies like wind, solar (photovoltaic) and hydropower are hence accounted for with an efficiency of $100 \%$ regarding the conversion of primary energy to final energy in the form of electricity. They therefore increase the total efficiency of the conversion sector and thus lower the primary energy consumption for a given electricity production.

Against this background, two important questions arise, i.e. (i) whether the European Union is on track to reach the energy efficiency target and (ii) which factors have been contributing or impeding target achievement. In this article, we focus on the achievement of the EU's primary energy target which should not exceed 1483 million tonnes of oil equivalent (Mtoe ${ }^{1}$ ) by 2020 (European Commission 2012, 2013). ${ }^{2}$.

Figure 1 shows the development of primary energy consumption in the EU28 for the period 2000-2014, as well as the abovementioned primary energy targets for 2020 and 2030. The graph also shows the reference evolution of primary energy projected by Capros et al. (2016) and Capros et al. (2008), based on which the $20 \%$ (2020) and 27\% respectively $30 \%$ (2030) energy efficiency targets were defined.

\footnotetext{
${ }^{1}$ One million tonnes of oil equivalent equals $41.868 \mathrm{pJ}$.

${ }^{2}$ According to the Energy Efficiency Directive EED (European Commission 2012), primary energy consumption is defined as gross inland consumption, excluding non-energy uses.
}

Primary energy consumption in the European Union grew rapidly in the first years of the new millennium (Fig. 1), but it levels off between 2004 and 2006. The economic crisis in the years 2008/2009 led to a clear drop, and, although there was a small recovery in energy consumption in 2010, primary energy consumption has been decreasing since then. In the last few years, progression towards the target of 1483 Mtoe for 2020 in the EU28 has been gaining pace.

Factors that may have influenced the achievement of the primary energy target include changes in activity levels (notably the impact of the economic development), structural changes, renewable energy policies, changes in the conversion sector, energy efficiency policies, autonomous energy savings and behavioural changes.

To identify the key determining factors for primary energy use and their impact, we conducted an index decomposition analysis (IDA) for primary energy consumption (PEC) of all Member States of the EU28. We focused on 2000 to 2014, as this period is relevant for policies like the European Energy Efficiency Directive (EED) 2012/27/EU (European Commission 2012) and statistical data are readily available. In this paper, we examine developments of primary energy consumption in the European Union and its Member States while we consider factors which had a strong impact on final energy consumption in an aggregated manner (i.e. we do not decompose energy use on the demand side by sectors and subsectors). The reason for this focus on primary energy lies in the fact that primary energy consumption plays a very important role in the set of targets of European energy policy, as outlined above.

In the past, studies applying IDA mostly focused on the comparison of countries or regions (within a country) regarding solely final energy consumption or $\mathrm{CO}_{2}$ emissions (e.g. Fernández González et al. 2013; IEA 2008; ODYSSEE-MURE 2015). The value added of the work performed for this article lies in the uniform definition of the different factors impacting primary energy consumption in the EU28 and its Member States, next to the alignment to EU policy goals expressed in primary energy terms. To our knowledge, no comparable studies are available.

We first describe the scope of our analysis of changes in primary energy consumption in the EU28 ("Methodology for the analysis of factors impacting primary energy consumption" section), then explain the data base and procedures to fill data gaps and the methods used ("Decomposition method and data" section). 


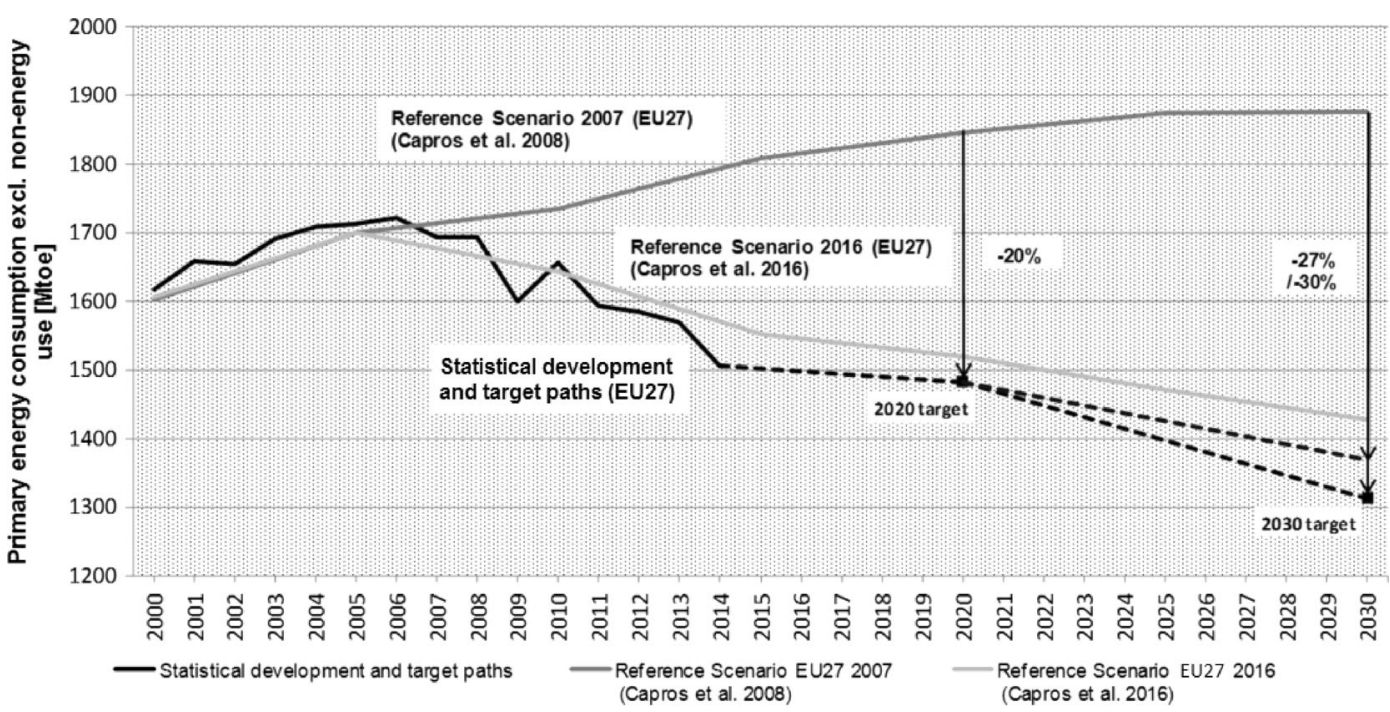

Fig. 1 Development of primary energy consumption (gross inland energy consumption excluding non-energy use.) in the EU27 for the period 2000-2014 compared to the reference scenarios developed in 2007 and in 2016 and to the energy efficiency targets

In the next step ("Results" section), we present the results for the EU28 as well as for two rather different EU Member States: first, for Germany which can be described as a state where the demand for energy consumption has reached a certain saturation level and where the transformation of the energy system towards long-term sustainability targets is strongly changing the composition of the conversion sector, as a consequence of the decision to phase out nuclear energy by 2020 and due to strong support for renewables, and second, for Poland, where further economic growth is expected and for which the conversion sector is characterised by large shares of fossil fuels, notably coal.

Finally, we discuss the results ("Discussion" section) and draw conclusions from the analysis ("Outlook and conclusion" section).

\section{Methodology for the analysis of factors impacting primary energy consumption}

\section{Definition of primary energy consumption}

Primary energy consumption for energy purposes, as displayed in Fig. 1, is defined in the EED (European Commission 2012) as the difference between "gross inland consumption" and "final non-energy consumption". Final non-energy consumption represents the use for 2020 and 2030 (these energy efficiency targets refer to the reference scenario developed in 2007; Capros et al. 2008, 2016; Eurostat 2016b)

of primary fossil fuels as lubricants and feedstock for material production (predominantly in manufacturing of chemicals).

Renewable energy technologies, which do not directly consume any fuels for generating electricity (i.e. wind, PV and waterpower), are accounted for with a primary energy efficiency of $100 \%$ by convention. Other types of renewable energy like biomass-based electricity are accounted with their actual conversion factors.

The various types of energy use considered in this paper are defined as follows (European Commission 2015a):

- Primary energy consumption = gross inland consumption - final non-energy consumption

- Gross inland consumption = primary production + primary product receipt + other sources (recovered products $)+$ recycled products + imports + stock changes - exports - bunkers - direct use

- Final non-energy consumption = non-energy use in conversion sector + non-energy use in energy sector + non-energy use in industry sector + non-energy use in transport sector + non-energy use in other sectors + non-energy use in industry, transformation and energy sectors ${ }^{3}$

\footnotetext{
${ }^{3}$ The last summand of this definition relates only to solid fuels (i.e. coal and coal products), which are not included in the other non-energy
} uses. 
- Energy available for final consumption = gross inland consumption - transformation input + transformation output + exchanges, transfers and returns - consumption of the energy sector - distribution losses

Factors impacting primary energy consumption

In this paper, we conduct a decomposition of primary energy consumption on two levels, the second being a part of the first one:

- Level 1: total primary energy consumption (excl. non-energy use)

- Level 2: primary energy consumption used for electricity generation

We split the analysis of primary energy consumption into these two parts, in order to analyse the electricity sector more in detail. Instead, one could have set up only one model with the electricity sector being split up immediately. However, some effects such as the penetration of electricity in the transformation sector would not have been clearly traceable.

First, the energy conversion sector is analysed as a whole by distinguishing three subsectors: electricity generation, heat generation and other transformations (which comprise the production of solid fuels, petroleum products, gas, renewable energy and wastes not used for electricity or heat generation) (see Fig. 2). Cogeneration of electricity and heat is divided between the subsectors electricity and heat, according to the methodology developed by Eurostat for their energy balances for their data collection on combined heat and power generation as based on the implementation guidelines as defined in Commission Decision 2008/952/EC (European Commission 2008). The third subsector "other sectors" bundles transformation activities where the changes were more limited than in the electricity and heat generation branches, or which present smaller activities, such as the production of solid fuels, petroleum products and gas. The level 1 analysis includes the own consumption of the conversion sector, distribution losses and the final energy consumption.

The second level (see Fig. 3) takes into account that changes in the electricity subsector may strongly impact primary energy consumption, hence the need to analyse changes in electricity generation and transmission/ distribution more carefully. It should be noted that the own consumption of the electricity generation and the electricity distribution losses are already included in the level 1 analysis.

Total primary energy consumption PE at level 1 in our analysis is decomposed into five factors, i.e.

$$
\begin{aligned}
\mathrm{PE}= & \sum_{i=1}^{3} \mathrm{FE}_{\mathrm{net}} * \frac{\mathrm{FE}_{\text {gross }}}{\mathrm{FE}_{\text {net }}} * \frac{\mathrm{FE}_{\text {gross }}^{\prime}}{\mathrm{FE}_{\text {gross }}} * \frac{\mathrm{PE}_{i}}{\mathrm{FE}_{\text {gross }, i}^{\prime}} \\
& =\sum_{i=1}^{3} \mathrm{FEC} * \mathrm{DL} * \mathrm{IEC} * \mathrm{STR}_{i} * \mathrm{EFF}_{i}
\end{aligned}
$$

where PE represents the total primary energy consumption and $\mathrm{FE}_{\text {net }}$ is depicting the total net final consumption, i.e. excluding internal consumption of power plant and distribution losses. $\mathrm{FE}_{\text {gross }}$ is defined as the gross final energy consumption including distribution and transmission losses ${ }^{4}$, but excluding the internal consumption of power generation equipment, while $\mathrm{FE}_{\text {gross }}^{\prime}$ includes both distribution and transmission losses as well as internal consumption of power generation. Index $i$ represents the three subsectors of the conversion sector in Fig. 2.

The factor FEC (substituting $\mathrm{FE}_{\text {net }}$ ) measures the changes in primary energy consumption due to changes of the net final energy consumption (without nonenergy use but including statistical differences). For some countries, however, these statistical differences can be comparatively large and may lead to different conclusions.

The factor DL (with DL $=\frac{\mathrm{FE}_{\text {gross }}}{\mathrm{FE}_{\text {net }}}$ ) shows the changes in primary energy consumption due to changing distribution losses. IEC (with IEC $=\frac{\mathrm{FE}_{\text {gross }}^{\prime}}{\mathrm{FE}_{\text {gross }}}$ measures the changes in PEC by the consumption of the energy sector, i.e. the consumption of auto-produced and purchased energy by energy producers and transformers in operating their installations. $\mathrm{STR}_{i}$ (with $\mathrm{STR}_{i}=\frac{\mathrm{FE}_{\text {gross }, i}^{\prime} \text { ) }}{\mathrm{FE}_{\text {gross }}^{\prime}}$ measures the changes in PEC caused by structural change in the energy sector, i.e. the shift in the shares of individual energy subsectors $i$, such as electricity, heat and other energy sectors (solid fuels, petroleum products, gas, renewable energies/wastes). $\mathrm{EFF}_{i}$ (with $\left.\mathrm{EFF}_{i}=\frac{\mathrm{PE}_{i}}{\mathrm{FE}_{\text {gross }, i}^{\prime}}\right)$ measures the changes in PEC caused by efficiency changes in the individual energy subsectors $i$ of the energy generation sector.

\footnotetext{
${ }^{4}$ Please note that Eurostat includes in the heading "distribution losses" both transmission and distribution losses (the latter represent losses at lower voltage levels and close to the consumer).
} 
Fig. 2 Structure for the level 1 analysis of changes in primary energy consumption

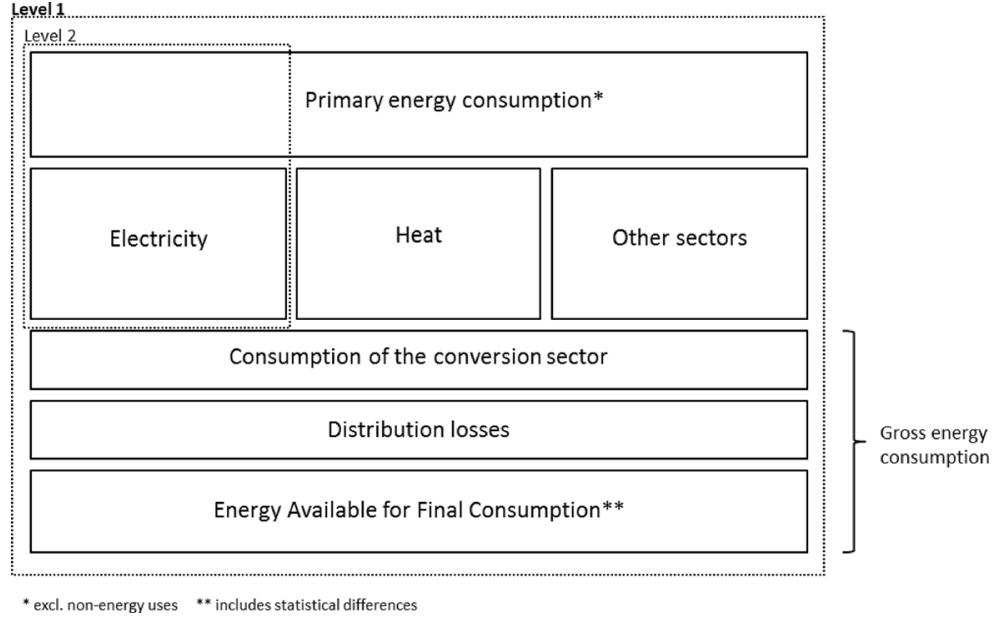

On the second level, we decompose PEC for electricity generation as follows:

$$
\begin{aligned}
& \mathrm{PE}_{\text {elec }}=\sum_{j=1}^{4} \mathrm{FE}_{\text {elec,gross }}^{\prime} * \frac{\mathrm{FE}_{\text {elec,gross }, j}^{\prime}}{\mathrm{FE}_{\text {elec,gross }}^{\prime}} * \frac{\mathrm{PE}_{\text {elec }, j}}{\mathrm{FE}_{\text {elec, gross }, j}^{\prime}} \\
& =\sum_{j=1}^{4} \mathrm{FEC}_{e} * \mathrm{STR}_{e, j} * \mathrm{EFF}_{j}
\end{aligned}
$$

where $\mathrm{PE}_{\mathrm{elec}}$ represents the primary energy used for the generation of electrical energy. The factor $\mathrm{FEC}_{e}$ measures the changes in PEC from changes in gross electricity consumption, which includes distribution losses and consumption of electricity in the energy sector. $\mathrm{STR}_{e, j}$ measures the changes in PEC from changes in the structure of gross electricity consumption regarding the source $j$ of energy, such as $\operatorname{RES} 100^{5}$, nuclear, electricity-only thermal power plants (including uncombined electricity regeneration from combustion-based renewables, in particular from biomass) or combined electricity generation from combined heat and power (CHP), including CHP based on renewables (note that heat generated from CHP is included in the heat section of the conversion sector).

$\mathrm{EFF}_{j}$ measures the changes in PEC from efficiency changes in the electricity generation by the different generation modes $j$ mentioned above.

\section{Decomposition method and data}

For our task of analysing the factors impacting primary energy consumption, we used index decomposition

\footnotetext{
$\overline{{ }^{5} \text { RES100: } 100 \%}$ efficiency renewable energies, e.g. wind energy, solar PV, hydro power, wave/ocean/tidal energy.
}

analysis (IDA) based on the most current Logarithmic Mean Divisia Index (LMDI) method.

IDA became a popular analysis tool in the 1980s and has been used by energy researchers to show the underlying factors of changes in energy consumption or $\mathrm{CO}_{2}$ emissions of a country or a region. Different methods were used over time and have certain properties, which can be seen as advantages or disadvantages. Ang (2004) examines several methods used for IDA in the past regarding theoretical foundation, adaptability, ease of use and ease of interpreting results.

Ang (2015) gives an overview of IDAs conducted in the time frame 2005 to 2014 and Ang and Zhang (2000) for studies up to 1999. In the most common designs of IDAs, the impacts of variations in overall activity level (e.g. gross value added), activity structure and energy intensity on the difference in total energy consumption in a specific sector - most of the time industry - and a

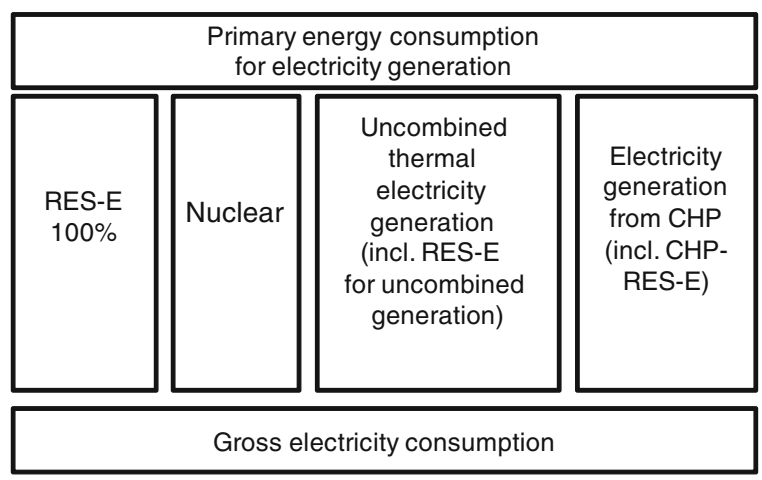

Fig. 3 Structure for the level 2 analysis of changes in primary energy consumption (Note: RES-E stands for renewable electricity) 
specific period are quantified. This approach is also extended to more sectors of a country's economy with a focus on the evaluation of specific energy policies in current studies (e.g. Colinet Carmona and Román Collado 2016). Recently, studies applying IDA also focused more on the decomposition of greenhouse gas emissions (e.g. Moutinho et al. 2016). In the past few years, analyses of ex ante (model) projections were conducted with regards to energy targets and policies (e.g. Smit et al. 2014). In our study, we apply IDA to primary energy consumption to evaluate the progress made in energy efficiency with regard to targets and policies for the European Union and its Member States. This multilevel analysis should provide further insight into the impact of policies linked to the reduction of primary energy consumption in the EU. As those energy efficiency changes cannot be divided into autonomous, policydriven and economy-driven improvements, we especially consider policies focused on renewable energy.

The Logarithmic Mean Divisia Index (LMDI) was introduced by Ang and Liu (2001) and is widely used today. The approach has two different versions, namely LMDI I and LMDI II, which differ mainly in the weighting function used and the ensuing properties.

In this study, we use LMDI I, which uses the logarithmic mean as the weighting function. The differences between LMDI I and LMDI II are explained in more detail by Ang et al. 2009.

The method was adopted as the preferred method by the International Energy Agency (IEA) substituting methods based on Laspeyres indices (IEA 2012). The main advantages of this method-besides other indextheoretical properties - lie in the fact that it produces no residual term (not attributed to any specific factor) and that it provides a linkage between additive and multiplicative decomposition (Ang et al. 2009). Disadvantages of the method are that the results might be difficult to communicate to non-experts and that the method is not defined for zeros or negative numbers in the data set due to logarithmic terms in the LMDI formulae. Two main strategies exist to handle this issue, namely the so-called analytic limit (AL) strategy as described by Wood and Lenzen (2006) and the small value strategy (SV) as introduced by Ang and Choi (1997). Although the AL approach would be theoretically superior to the latter, we use the SV strategy (with values smaller than $10^{-20}$ ) as recommended by Ang and Liu (2007) as a substitute for zero values, as the share of zero values in our data base is very limited.
The additive form of the LMDI approach follows these general equations:

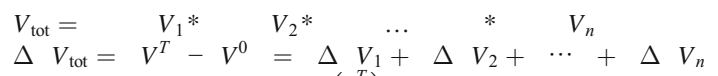

$$
\begin{aligned}
& \text { where } \Delta V_{x}=\sum_{i} L\left(V_{i}^{T}, V_{i}^{0}\right) \ln \left(\frac{x_{i}^{T}}{x_{i}^{0}}\right) \text { with } L(a, b)=(a-b) /(\ln a-\ln b)
\end{aligned}
$$

Here, $V$ describes an aggregate (e.g. energy consumption) for a subaggregate $i$ (e.g. an energy branch, such as heat or electricity) which is composed of different factors $x$ and its changes in the time period 0 to $T$ for which the decomposition is conducted (see Ang 2005). The decomposition of changes in primary energy consumption $\mathrm{PE}$ according to Eq. (1) can be formulated as follows:

$$
\begin{aligned}
\mathrm{PE}^{\mathrm{T}}-\mathrm{PE}^{0}=\Delta \mathrm{PE}_{\mathrm{tot}}= & \Delta \mathrm{PE}_{\mathrm{FEC}}+\Delta \mathrm{PE}_{\mathrm{DL}} \\
& +\Delta \mathrm{PE}_{\mathrm{IEC}}+\Delta \mathrm{PE}_{\mathrm{STR}} \\
& +\Delta \mathrm{PE}_{\mathrm{EFF}}
\end{aligned}
$$

where the factor $\triangle \mathrm{PE} \mathrm{EFF}_{\mathrm{EF}}$ for example would be built as follows:

$$
\Delta \mathrm{PE}_{\mathrm{EFF}}=\sum_{i} L\left(\mathrm{PE}_{i}^{T}, \mathrm{PE}_{i}^{0}\right) \ln \left(\frac{\mathrm{EFF}_{i}^{T}}{\mathrm{EFF}_{i}^{0}}\right)
$$

with $\mathrm{EFF}^{T}$ and $\mathrm{EFF}^{0}$ describing the value of conversion efficiency at a given point in time for the energy branch $i$ as defined in Eq. (1) (see Ang 2015).

$L(a, b)$ describes the logarithmic mean of two positive real numbers - in this case, different aggregates of primary energy consumption of the first $(0)$ and last year $(T)-a$ and $b$, which is used as the weighting function in LMDI I.

In this paper, we apply the LMDI method as periodwise decomposition, which means that decomposition is applied to explain the difference between the first and the last year of the time series considered. This requires much less data and computation than time series decomposition (i.e. yearly decomposition).

As statistical foundation of this analysis, we used publicly accessible data for EU28 and its Member States from the European Central Statistical Office Eurostat. Our database was compiled with bulk data from the tables "Simplified energy balances" (table code nrg100a), "Supply, transformation and consumption of electricity" (nrg105a), "Supply, transformation and consumption of heat" (nrg106a) and "Supply, transformation and consumption of renewable energy" (nrg107a) 
of Eurostat's energy statistics database. ${ }^{6}$ In total, about 20,329 data series (i.e. time series of data representing a certain aspect) or 701 different data series per country were used in our analyses.

The available statistics do not distinguish between the following cases (all these reported as ":", " 0 " or " $0.0 ")$ :

- Data are not available to the reporting authority.

- Data are confidential and not shown.

- Energy quantity is a real zero (no consumption).

- Consumption is negligible (quantity is less than 0.5 of the respective reporting unit).

All cases except for the third may cause problems, but especially the last can cause inconsistencies, as the sums of subaggregates may differ slightly from aggregates given in data.

Within the dataset used for the analysis, only a few crucial values were missing. Single missing values for some countries like Poland, Hungary and Croatia were estimated based on time series: as these consisted of zeros, for the most data points, they were assumed to be zero also for all the remaining parts of the time series. For Germany, for example, some greater parts of time series regarding petroleum products were missing, such as distribution losses and transformation inputs for heating plants. These gaps could be filled by data taken from the National Energy Statistics compiled by AGEB? .

For other countries like Latvia, Cyprus and Malta, a large number of crucial time series were missing. Since the validity of the decomposition results for these countries can be expected to be strongly influenced by imputations, we excluded these countries from our analysis. This is justified by the small proportion of the energy consumption of these countries compared to the European Union as a whole.

Furthermore, due to a rather broad definition of CHP in the energy balances published by Eurostat, which resulted in extraordinarily large CHP shares in electricity generation, adaptations of these numbers based on Eurostat's dedicated CHP statistics according to Directive 2012/27/EC were made. This allowed to establish a more realistic picture of CHP by recalculating its gross

\footnotetext{
$\overline{6}$ http://ec.europa.eu/eurostat/data/database

${ }^{7}$ Arbeitsgemeinschaft Energiebilanzen. http://www.agenergiebilanzen.de
}

electricity generation. Missing values in the time series, e.g. for the year 2014, were determined using a simple exponential smoothing model (see Gardner 2006) for ease of calculation and because trend and seasonal components play at most a minor or no role in the CHP time series considered.

\section{Results}

While the analysis was carried out for the European Union as a whole and most of its Member States (except Latvia, Malta and Cyprus), we will focus only on two countries besides the EU28: we selected Germany and Poland for a detailed comparison, as they represent good examples for countries whose energy system is undergoing transition on different levels of advancement towards the European Union target. Germany represents a state where the demand for energy consumption has reached a certain saturation level (variation of $\pm 6 \%$ within the last 15 years) and where the transformation of the energy system towards long-term sustainability targets has strongly changed the composition of the transformation sector, in preparation for the country's phase-out of nuclear energy by 2020. At the same time, Germany's conversion sector is dominated to a certain degree by fossil fuels with a share of coal in gross electricity generation of almost 42\% (AGEB 2016). On the other hand, Poland represents a state which is still expected to enjoy economic growth and for which the transformation system is still characterised by fossil fuels and a remarkably low share of electricity generation from renewable sources of $12.4 \%$ in 2014 (Eurostat 2016a).

The total decrease in primary energy consumption by about 110 Mtoe in the European Union in the period 2000 to 2014 was mainly achieved by three countries (explaining a total of 84 Mtoe), namely the UK, Germany and Italy (see Table 1, Annex). Smaller contributions were made by a second group of a total of 16 countries amounting to a decrease of almost 40 Mtoe; a third group consisting of six countries increased their energy use by a total of about 13 Mtoe (see Fig. 4).

Final energy consumption decreased most strongly in the UK (by around 37 Mtoe), followed by Germany ( 25 Mtoe) and Italy (22 Mtoe). In contrast, final energy consumption increased most in Poland (5 Mtoe), followed by Austria and Finland with around 4 and 2 Mtoe respectively. 
Table 1 and Table 2 (see Annex) show the summarised results for both levels of decomposition for the EU28 and all Member States (except Latvia, Cyprus and Malta).

Decomposition of primary energy consumption for the EU28

Factors impacting overall primary energy consumption 2000-2014

Over the period 2000 to 2014 , total primary energy consumption in the EU28 dropped by about 110 Mtoe or 7\% (see Figs. 1 and 5). Most of this change can be attributed to lower final energy consumption in this period ( -98 Mtoe), of which -37 Mtoe is related to electricity, -5 Mtoe for heat and -56 Mtoe for other conversion sectors. The main decrease occurred in the industry sector, the final energy consumption of which dropped by almost $18 \%$ in this time period, while overall final energy consumption in the EU28 decreased by only $6 \%$. Decreases in distribution losses and the conversion sector consumption ${ }^{8}$ accounted for around -1.5 and -4 Mtoe respectively.

A further explanatory factor for the decrease has been the improved conversion efficiency in the energy system from 41 to $44 \%$ in this period, which is mainly linked to the rising share of renewable energy in gross electricity generation from $14.4 \%$ in 2004 to $27.5 \%$ in 2014 (Eurostat 2015b). This effect is strongly compensated by structural changes in the structure of the energy conversion sector, leading to an increase of about 41 Mtoe, in particular due to a shift towards higher shares of electricity. The underlying reason is the lower overall conversion efficiency of electricity generation compared to the production of heat and other types of final energy. While the changes in the structure of electricity generation alone would have resulted in a decrease by about 53 Mtoe, the changes in other subsectors of the conversion sector (solid fuels, petroleum products, gas and renewable energies/wastes) reduced this effect to approximately $48 \mathrm{Mtoe}$. In total, the effects of otherwise noticeable net efficiency gains due to the increased generation and use of renewable electricity are limited.

\footnotetext{
${ }^{8}$ The conversion sector consumption in the EU28 as a whole mainly consists of own use in electricity, CHP and heat plants and consumption in petroleum refineries.
}

Factors impacting primary energy consumption due to electricity generation 2000-2014

In the time period considered, the total change of primary energy consumption attributable to the generation of electricity (level 2 of our analysis) resulted in around -23 Mtoe (see Fig. 6).

An increase in gross electricity generation by about $5 \%$ added 30 Mtoe to primary energy consumption. A decrease of nearly 11 Mtoe occurred as a consequence of higher overall efficiencies in electricity generation. Structural changes in the electricity generating sector contributed a decrease of 42 Mtoe on the primary energy consumption. The main driver for this strong reduction was the lower electricity generation in thermal and nuclear power plants, which contributed a reduction by 48 and 29 Mtoe respectively. The replacement of this form of power generation by renewable energy sources and $\mathrm{CHP}^{9}$ resulted in an increasing effect of 28 Mtoe (RES100) and 8.5 Mtoe (CHP) respectively. This resulted in an increase in the conversion efficiency of electricity generation by about $4 \%$ due to the penetration of RES100 and CHP plants, at the expense of thermal and nuclear power generation.

\section{Comparison of Germany and Poland}

In the context of the overall EU 20\% energy efficiency target, Germany had proposed an indicative target for primary energy consumption in 2020 of 276.6 Mtoe and Poland of 96.4 Mtoe (European Commission 2015b) (see Fig. 7). While Poland has stayed below its targeted primary energy consumption, Germany was still facing a gap of about 5\% in 2014. The 2030 energy efficiency target of at least $27 \%$ is only set for the European Union as a whole, compared to the PRIMES 2007 baseline by Capros et al. (2008) (European Commission 2014). Assuming a uniform target of $27 \%$ for all Member States based on the 2030 target of the European Union, Poland has to reduce its primary energy consumption by about $2.4 \%$ from 2014 until 2030 to reach an assumed target of $87 \mathrm{Mtoe}$, while Germany faces a gap of almost $26 \%$ to a hypothetical 2030 target of 217 Mtoe, based on the reference projections according to PRIMES 2007. The assumption of a uniform energy efficiency target for all Member States may be challenged as,

\footnotetext{
${ }^{9}$ Please note that at the level 2 decomposition analysis, the penetration of renewables with $100 \%$ nominal efficiency and of CHP appears as a structural effect, due to the better disaggregation of effects at that level. At the level 1 analysis, this appears as an efficiency improvement.
} 


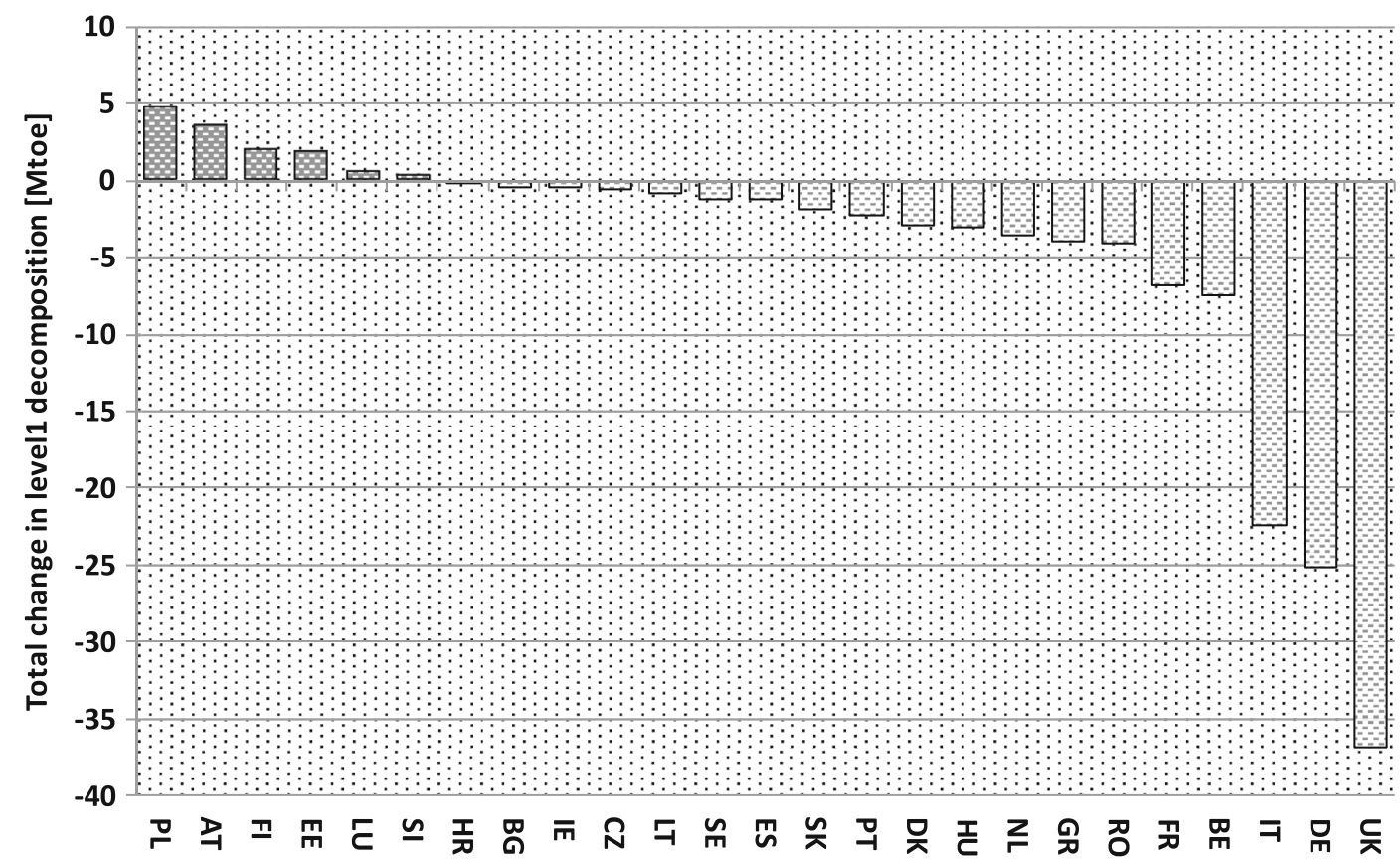

Fig. 4 Comparison of the total changes in level 1 decomposition for 25 Member States (The total of EU28 and the sum over all countries may slightly differ due to the missing data for the Member States Malta, Cyprus and Latvia.) (during the period 2000-2014)

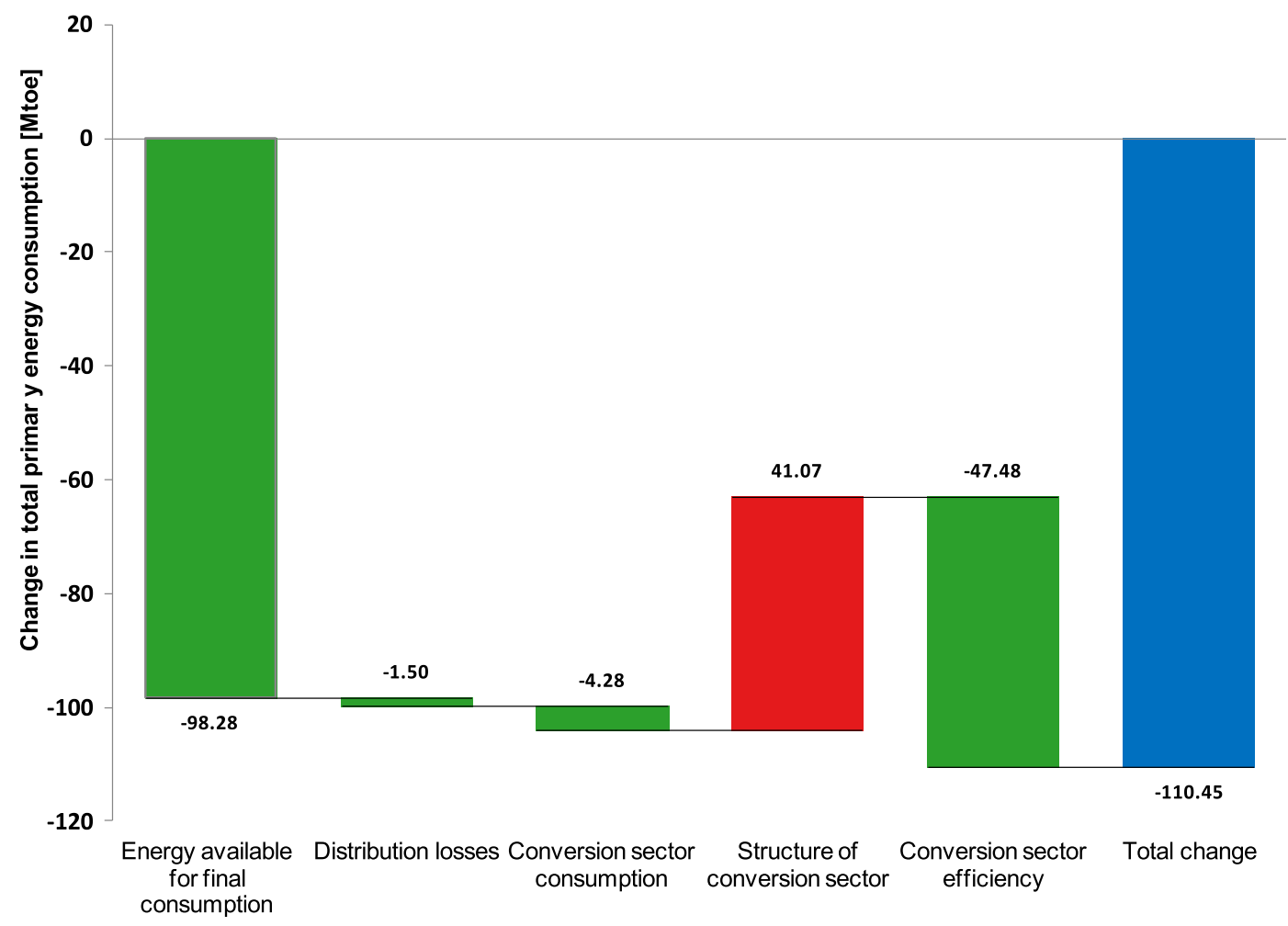

Fig. 5 Decomposition of the change in total primary energy of the EU28 for the period 2000-2014 by different factors 


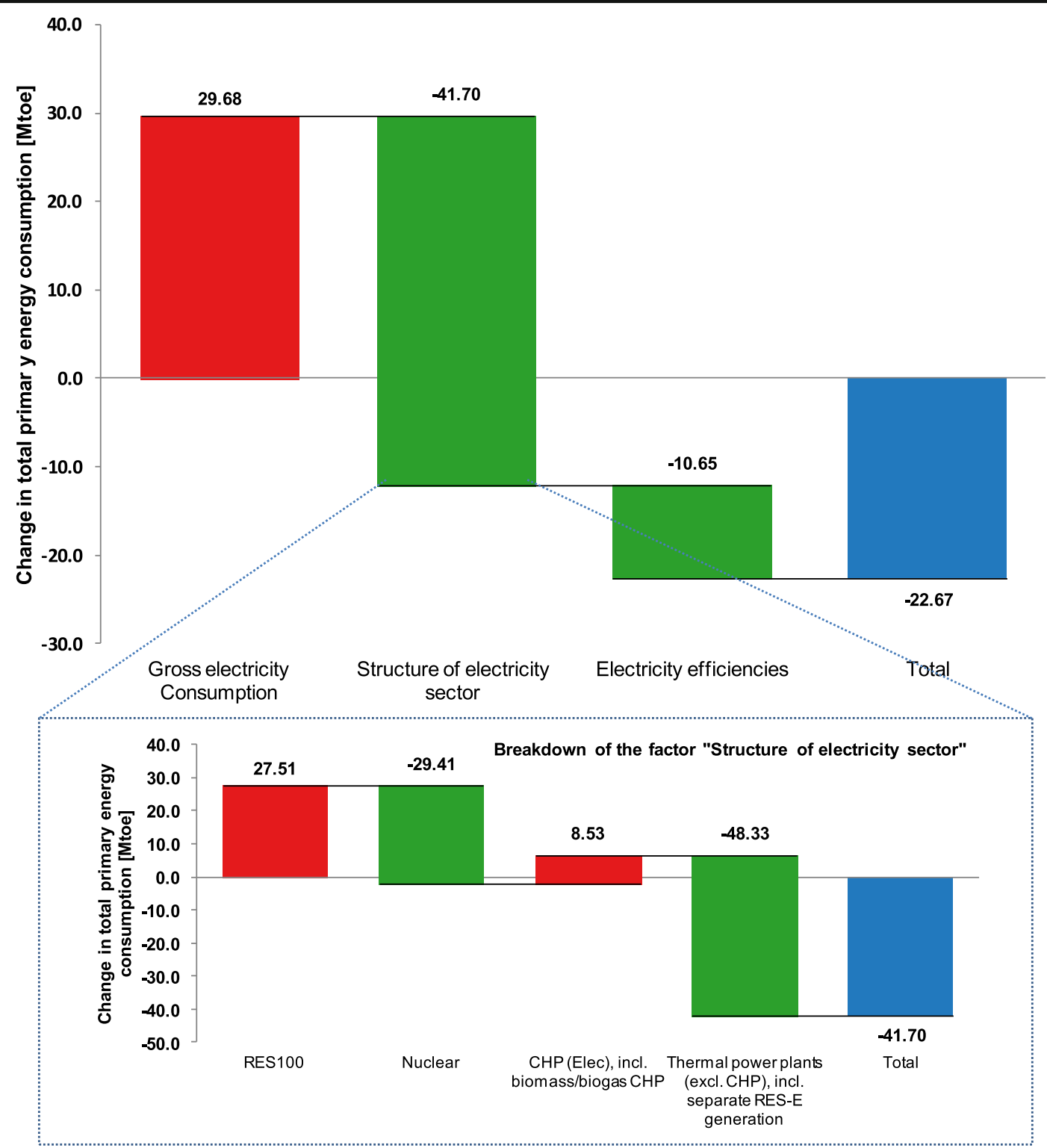

Fig. 6 Decomposition of primary energy consumption due to electricity generation for the EU28 for 2000-2014

with respect to greenhouse gas emissions, there is an effortsharing existing for 2020 (European Parliament 2009) and proposed for 2030 (European Commission 2016a), at least for the sectors not concerned with emission trading. However, two arguments can be brought forward for a uniform target: First, in the energy efficiency field, only an overall EU target exists and no effort-sharing is proposed at the political level, neither for 2020 nor for 2030. Second, Fraunhofer-ISI et al. (2014) have shown that there are comparable energy efficiency potentials across all EU Member States. This is due to the fact that, for example, in the residential sector there is still a considerable potential for improvement between the present building stock and a building stock with nearly zero energy consumption, despite some differences in the present level of energy efficiency among EU Member States.

The targets for the share of renewable energies in gross final energy consumption in 2020 according to Directive 2009/28/EG were set to $15 \%$ for Poland and to $18 \%$ for Germany (European Commission 2009).

\section{Decomposition analysis for Germany 2000-2014}

The German government has set itself several national targets for the year 2020, in particular, the objective of 


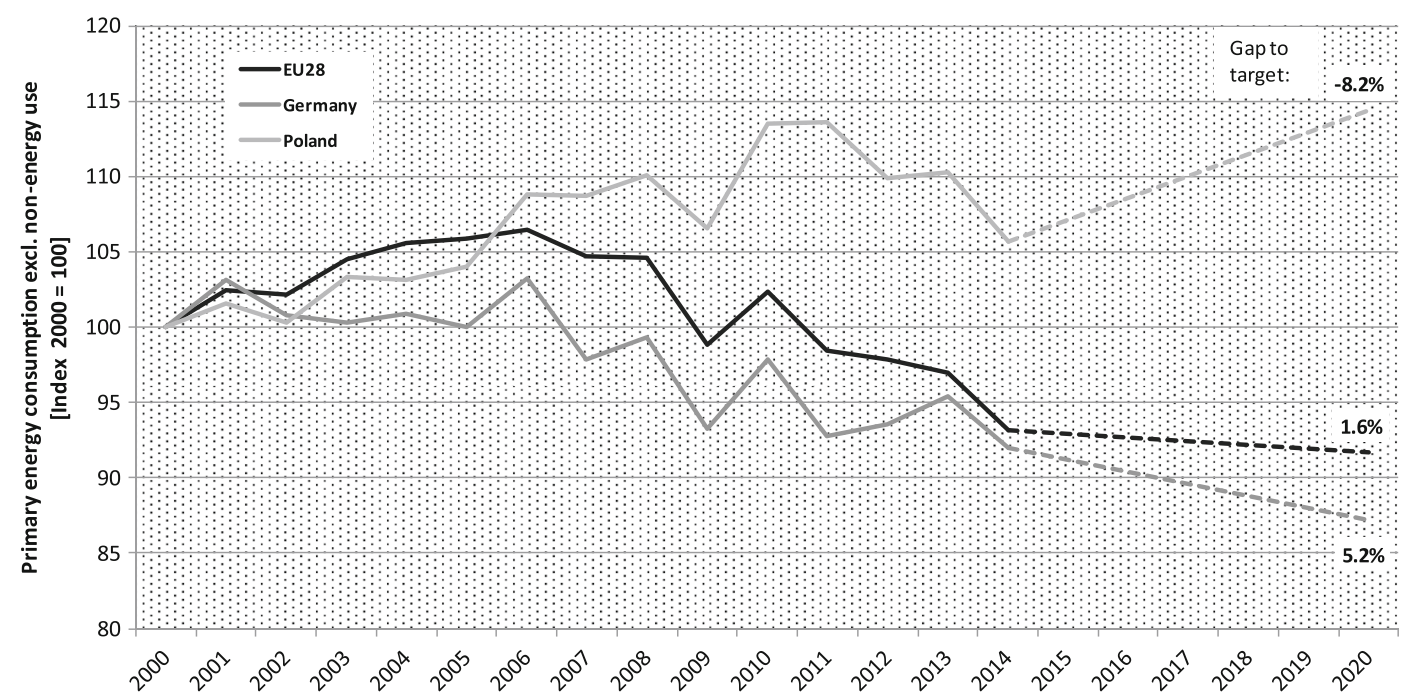

Fig. 7 Historic development of primary energy consumption (index) for the EU28, Germany and Poland and the gap to their 2020 targets (as proposed in European Commission 2015b). A negative value implies that the proposed target is already reached

increasing the share of electricity generated by CHP plants to $25 \%$ of total electricity generation, a share of $35 \%$ renewable energy in gross electricity consumption and a reduction of GHG by $40 \%$ compared to 1990 . Furthermore, there is a national energy efficiency target of $-20 \%$ in 2020 compared to 2008 regarding primary energy consumption (BMWi 2014, p. 5).

In our IDA on level 1, we find that the changes in final energy consumption had the largest impact on Germany's PEC in the period 2000-2014 with almost 20 Mtoe (see

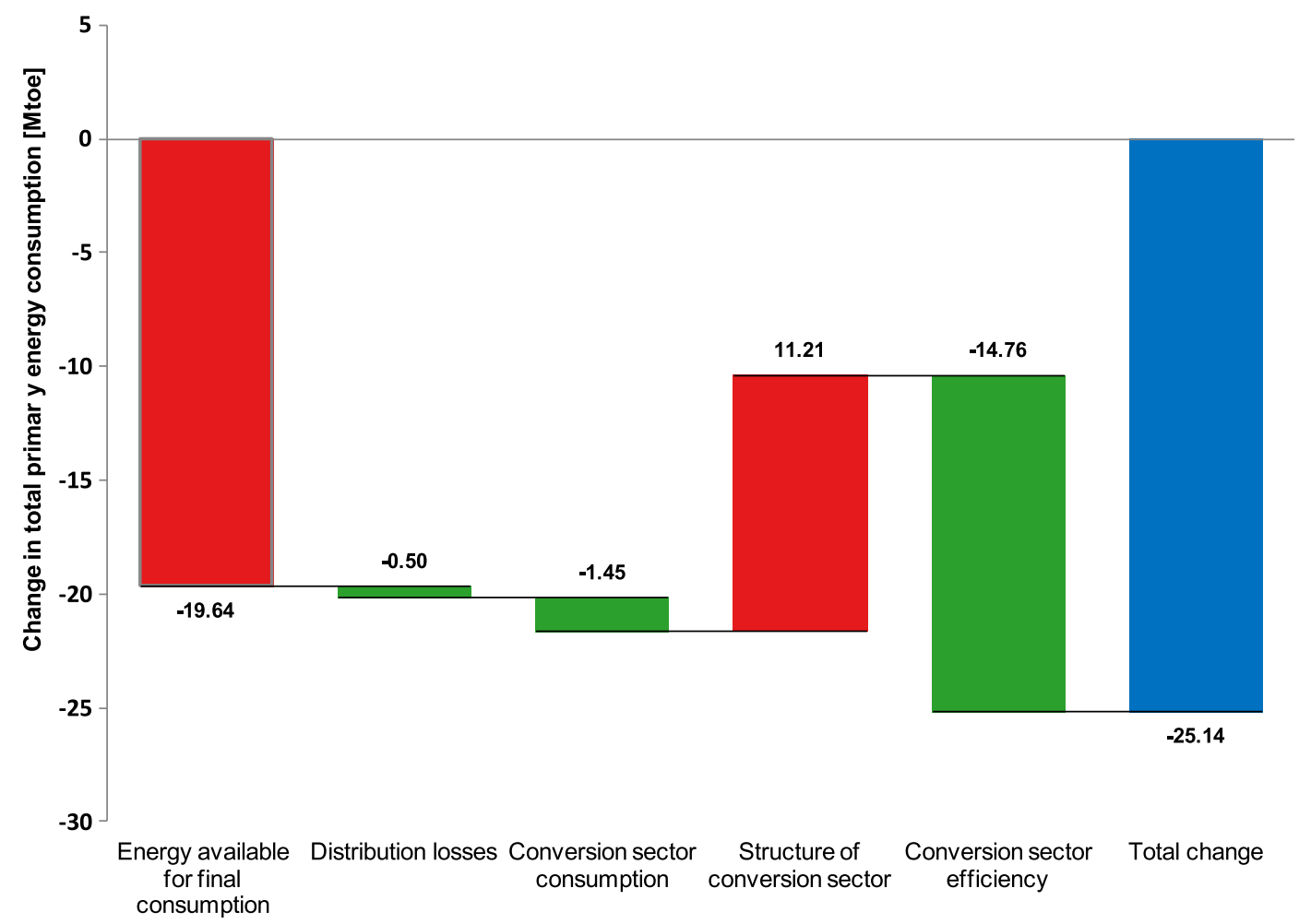

Fig. 8 Level 1 decomposition of primary energy consumption for Germany for 2000-2014 


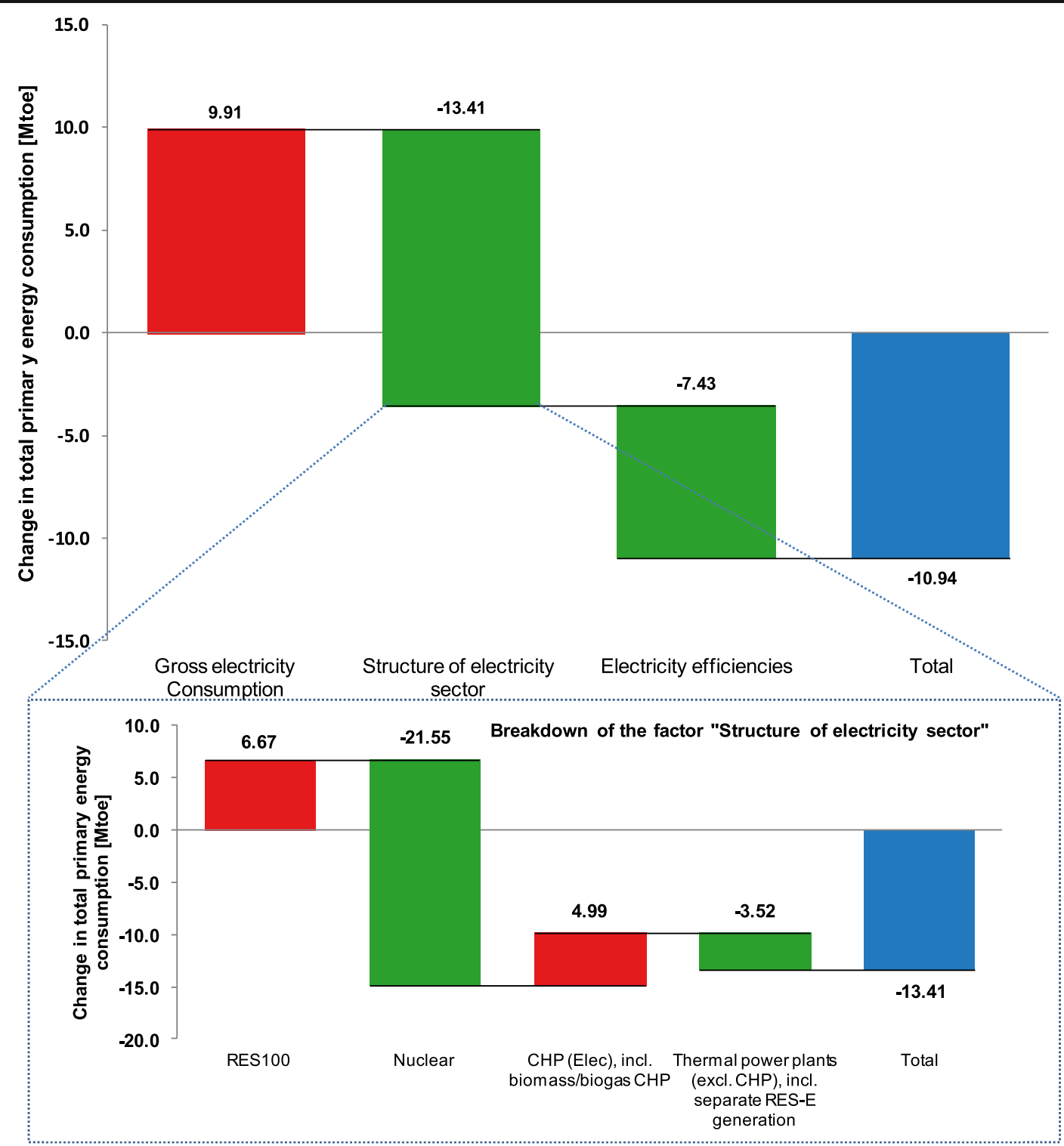

Fig. 9 Level 2 decomposition for Germany for 2000-2014

Fig. 8). These energy savings were mainly achieved in the transport and residential sectors. The second largest effect is the rising efficiency of the conversion sector with around 15 Mtoe. This reduction effect is mainly due to a rapid development of renewable electricity generation from $6.6 \%$ in 2000 to $27.4 \%$ in 2014 and an accompanying increase in efficiency of total electricity generation from 38.9 to $45.3 \%$ in the same period (AGEB 2015).

As a counteracting effect, the structural change towards more electricity leads to an increase by around 11 Mtoe. Together with the slightly decreasing effects by lower distribution losses and consumption in the conversion sector, all effects together resulted in a total change in PEC of 25 Mtoe.

On the second level of our decomposition, dealing with the electricity sector, we identified the changed structure of the conversion sector to contribute most to the change of primary energy consumption for electricity generation (see Fig. 9). The decrease amounts to around $13 \mathrm{Mtoe}$, which is mainly linked to the gradual phase-out of nuclear energy in Germany and the drop of its share in electricity generation from $29.5 \%$ in 2000 to $15.5 \%$ in 2014 ( -22 Mtoe). This was substituted by renewable energy sources with $100 \%$ nominal efficiency (6.1 to $17.6 \%$ in 2013) and electricity 
generation by CHP (10.6 to $12.4 \%$ in 2013), which account for increasing effects of 7 and 5 Mtoe respectively. As nuclear energy is accounted for in the energy balances with a nominal efficiency of $33 \%{ }^{10}$ (Eurostat 2015a), this substitution leads to an overall higher efficiency in electricity generation, as can be seen in the level 1 decomposition.

The growing gross electricity consumption $(+3 \%)$ counteracted other effects with a resulting additive effect of about 10 Mtoe. Together with changes in the efficiencies mainly of thermal power plants, which had a slightly increasing effect of 7 Mtoe, the total primary energy savings due to the electricity sector in Germany amount to 11 Mtoe.

\section{Decomposition analysis for Poland 2000-2014}

Our first-level analysis regarding Poland shows differing developments compared to Germany. While the increasing final energy consumption amounted to an increasing effect of about 10 Mtoe from 2000 to 2014, all other factors lowered the primary energy consumption (see Fig. 10).

The largest reducing effect with 2.3 Mtoe is due to a decreased consumption in the conversion sector, which dropped by $11 \%$ in the period considered. In contrast to the developments in Germany, the changes in the structure of the conversion sector had a decreasing effect on the primary energy consumption in Poland, as the consumption of electricity is growing, but the share of electricity declined slightly due to the more rapidly growing consumption of energy carriers like solid fuels, petroleum products, gas and waste. While the total energy provided by the conversion sector grew by around $17.5 \%$, the structure within the sector changed only slightly, with primarily lower heat production resulting in a negative effect of 1.5 Mtoe. Changes in the efficiency of the conversion sector in Poland also had a reducing effect of about 1.2 Mtoe. The overall efficiency of electricity generation in Poland increased only slightly, while the main gains in efficiency are accounted for in "other energy sectors" which besides renewable energy like biomass and waste (i.e. nonRES $100^{11}$ ) also include refineries, where the total conversion efficiency increased from 97.9 to $99.2 \%$ from

\footnotetext{
${ }^{10}$ This corresponds to the average thermal efficiency of nuclear power plants in the European Union. This nominal efficiency is assumed, if no actual values are available (which is predominantly the case).

${ }^{11}$ These renewable energies are accounted for with their actual conversion efficiencies other than $100 \%$.
}

2000 to 2014. Considering also a slight decrease in distribution losses ( $-0.5 \mathrm{Mtoe})$, the total effect of changes was a reduction of primary energy consumption of 4.7 Mtoe.

On the second level of our decomposition, the rise in electricity consumption in Poland had the largest effect on the primary energy consumption of electricity generation with an increasing effect of 2.5 Mtoe. This main effect was reduced by changes in the structure of the electricity generation sector, which amounted to about -0.6 Mtoe (see Fig. 11). The structure effect of +0.55 Mtoe is composed of a slight increase in RES100 from 2.8 to $6.5 \%$ of gross electricity consumption, resulting in an increasing effect of $0.5 \mathrm{Mtoe}$, and a slight increase in the share of CHP, which resulted in an effect of +0.11 Mtoe, combined with a slightly decreasing share of thermal power plants and Non-RES100 electricity generation contributing a decrease of around 1 Mtoe.

The changes of efficiencies in the electricity generation contributed an increasing effect of $0.15 \mathrm{Mtoe}$, as the efficiency of thermal power plants declined slightly between 2000 and 2014.

\section{Discussion}

In the first part of this section, we discuss the main results, while we focus on methodological choices in the second part.

On the EU28 level, our analysis shows an overall decline of PEC by 110 Mtoe from 2000 to 2014.This decrease in PEC was mainly driven by increasing overall efficiency in electricity generation and reduction of final energy consumption. These effects were counteracted mainly by changes in the structure of the conversion sector due to increased shares of electricity. However, this development is not necessarily apparent for the interim years. While we observe a reduction of PEC by almost $7 \%$ for the period from 2000 to 2014 , some interim years show an increase, with a maximum of $6 \%$ in 2006 compared to 2000 . An overall decreasing trend is only visible in the most recent years. Although these changing developments can be partially attributed to weather effects, economic activity also influenced this development.

Our analyses show that the drivers for primary energy consumption in the various states differ, depending on the changes in the energy system and macroeconomic developments (see the tables in the annex). Many 


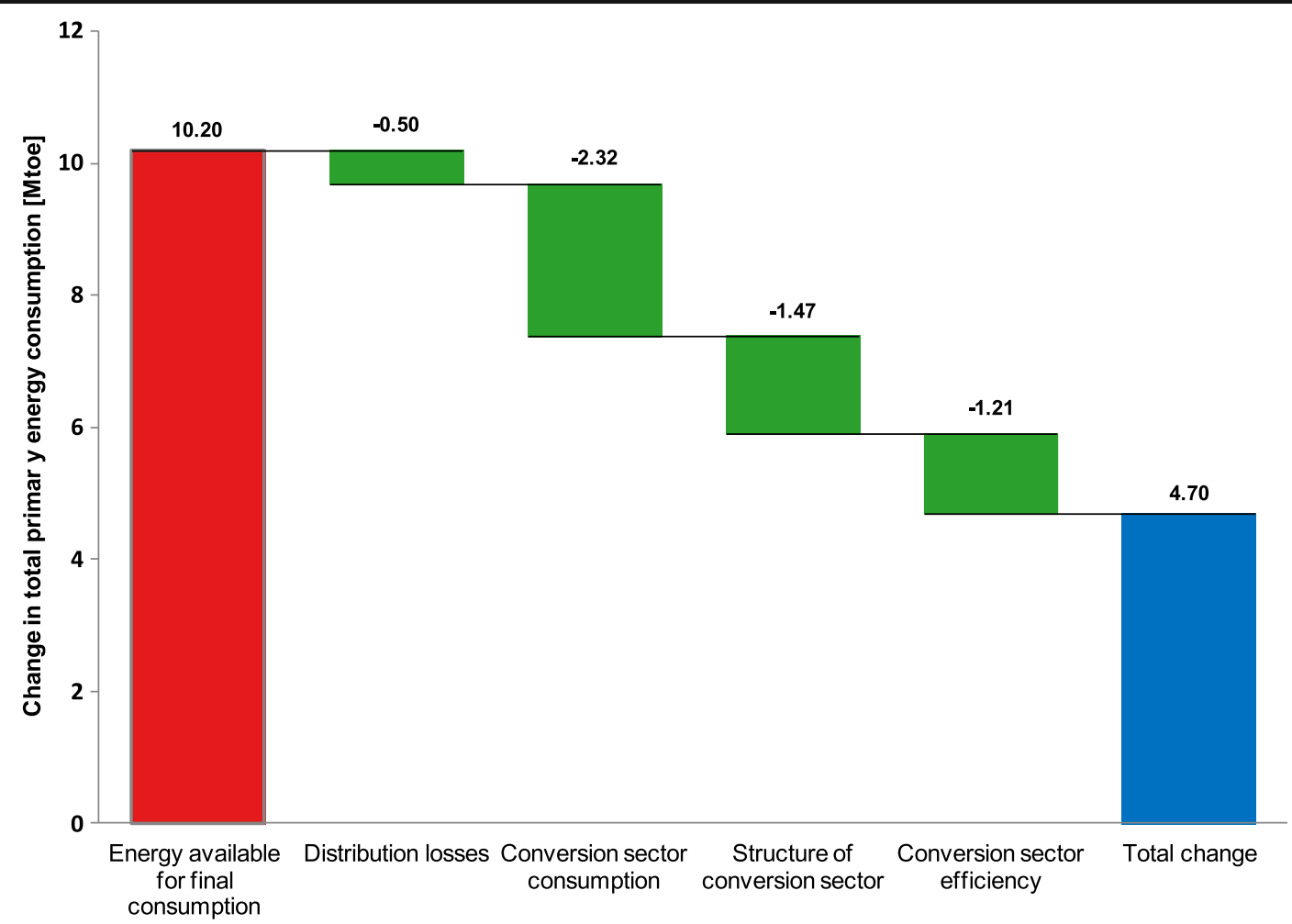

Fig. 10 Level 1 decomposition for Poland for 2000-2014

countries, which are not part of the EU15 (i.e. entered the European Union after April 2004), show rising final energy demand over the time period considered, which is primarily due to increasing consumption in electricity and "other energy sectors" rather than heat consumption. In the EU15 Member States, this increase in final energy consumption is not observed, with a few exceptions like Finland and Austria. While almost all countries show structural effects resulting in increasing energy use, these are far more significant in EU15 states, due to the increased importance of electricity. In these countries, the structural effect driving energy use upwards is counteracted in most cases by increasing overall energy efficiency in the conversion sector.

Most of the changes at European level are caused by only a few states, namely the UK, Germany and Italy. However, the individual contribution of the different factors can vary considerably: In UK, for example, the change was mostly driven by reduction of final energy consumption, while in Germany increasing efficiency in the energy conversion sector was a major contributor to the overall reduction. In Italy, both the reduction in final consumption and improved efficiency in the conversion sector, combined with a more moderate penetration of electricity, strongly drove down primary energy consumption.

We estimated or interpolated as few data points as possible. In the case of larger data gaps, other national data were used to close those gaps (e.g. for Germany).

Furthermore, the unrealistic representation of CHP in Eurostat's energy balances called for the use of other data published by Eurostat (i.e. table "tsdcc350"), based on a different methodology. In order to ensure consistency of the dataset, the differences related to the changed accounting of CHP generation were incorporated in other related subaggregates (in particular into the transformation input for thermal power plants, as it can be supposed that an overestimation of the CHP share leads to an underestimation of fuel input for thermal power plants).

Also, a country's PEC is influenced by weather and climate, mainly through space heating-related final energy consumption of households and services as well as - to a much lesser extent - primary energy consumption of (heat-controlled) CHP. To assess this impact, further analysis including climate-adjusted energy consumption would be required. For the moment, this influence is included in the aggregate factor representing all demand-side changes. 


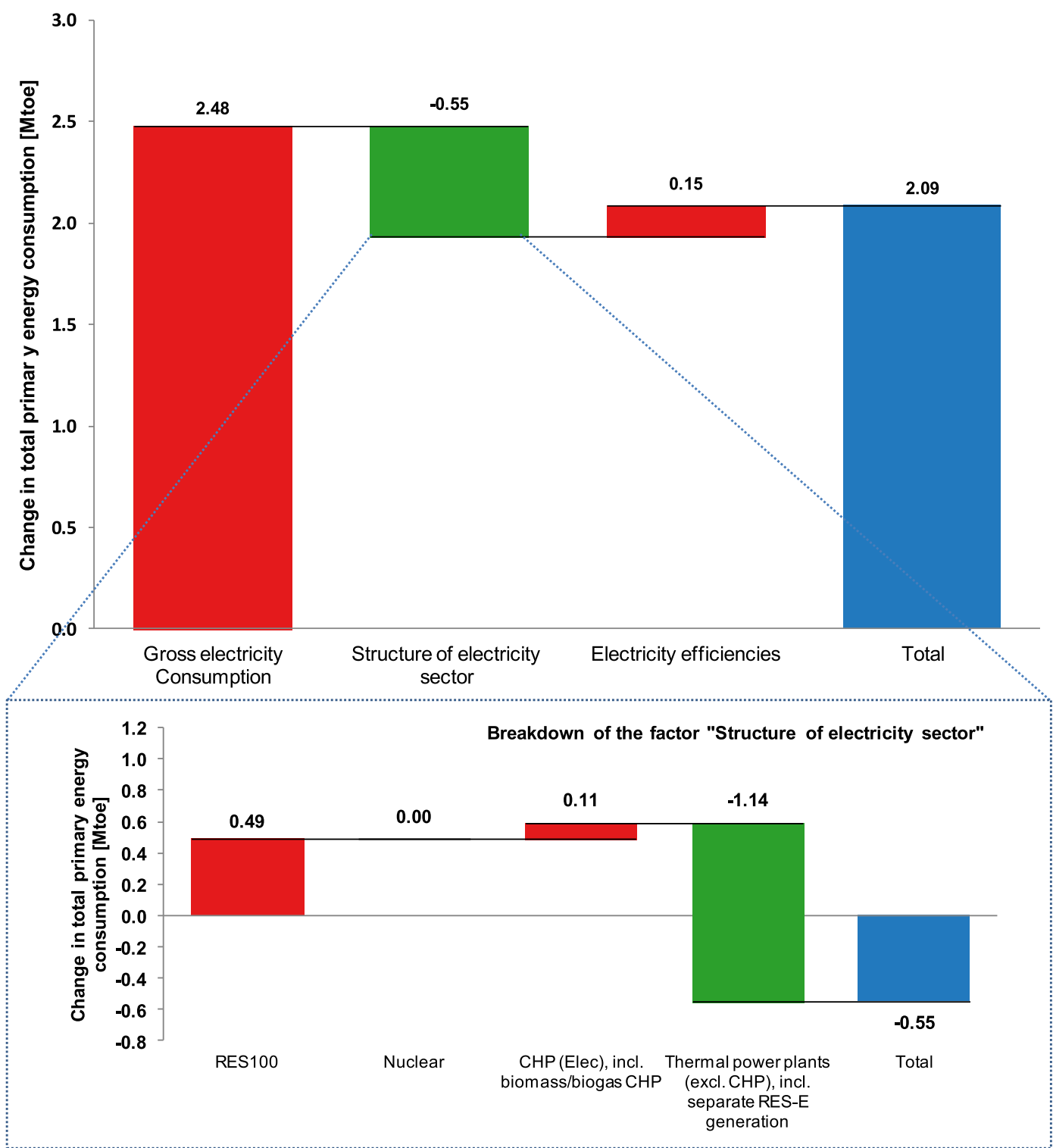

Fig. 11 Level 2 decomposition for Poland for 2000-2014

\section{Outlook and conclusion}

With a PEC of 1507 Mtoe in the EU28 in 2014, there is currently a gap of $1.6 \%$ to the intended PEC target of 1483 Mtoe in 2020. Germany faces a difference of 5\% to its target while Poland has been below its targeted PEC level since the year 2000. The Member State targets proposed by each country for 2020 (European Commission 2015b) do not add up to the overall $20 \%$ energy efficiency target of the EU. Almost all non-EU15 countries (except Bulgaria, Malta and Estonia) already reached their 2020 targets in 2014 or remained below the targeted primary energy consumption so far. But only a third of the old Member States (EU15) already reached their 2020 goal in 2014, while others show a gap ranging from $1 \%$ (FR) to 14\% (EL) in 2014 (see Fig. 12 in Annex).

In the EU15 countries, the increasing effects on level 1 were mostly due to structural effects attributable to rising shares of electricity, which were counteracted mainly by increasing efficiency in electricity generation and drops in final energy consumption. Non-EU15 countries as a group show a more mixed development. Here, the strongest drivers towards increased energy use were the rising final energy consumption or structural effects of the 
conversion sector (i.e. switch to electricity), which were counteracted by rising efficiencies, dropping energy consumption in the conversion sector and lower losses in transmission and distribution. On the second level of our analysis, i.e. the change in primary energy consumption due to changes in the electricity sector, the main driver for increased primary energy demand in the EU28 was the higher electricity generation, of which Germany and Spain contributed about a third. This effect was mainly counteracted by changes in the structure of the electricity sector, especially due to the decreasing share of thermal and nuclear power plants and their substitution by RES100 and CHP. The decline in the share of nuclear power is mainly driven by Germany's nuclear phase-out.

Overall, changes in the structure and efficiency of the conversion sector and its electricity generation drove down the EU's primary energy consumption (from 2000 to 2014?) towards the 2020 target. These dynamics were mainly linked to the penetration of renewable energy sources and the substitution of other technologies in the conversion sector. This implies that the decrease in primary energy consumption in the EU may be closely related to policies encouraging renewable energy and CHP and their penetration in the conversion sector. The effects of policies targeting demand-side energy efficiency are not visible directly in our analysis, as they are included in the changes in final energy consumption which is also influenced by many other drivers in the various sectors, in particular, economic development and weather effects or behavioural influences. An econometric modelling approach as applied by ICF (2016) to measure the impacts of certain policies might be useful to separate these different effects.

As a next step, an in-depth analysis of the development of final energy consumption and the influencing effects should be conducted, as this is one of the most important drivers of primary energy consumption, besides changes in structure and efficiency in the conversion sector. Furthermore, the application of such a decomposition analysis to relevant ex ante model data (e.g. PRIMES) at the level of primary and also final energy could help in evaluating the effects of policies and targets achievement. To identify impacts of energy policies more clearly and to deal with the non-causality of standard IDA, also a comparative decomposition of different $e x$ ante scenarios could be conducted to link developments to specific policies, similar to the study by Agnolucci et al. (2009) on the reduction of $\mathrm{CO}_{2}$ emissions.

While the reduction of primary energy consumption in the EU as a whole seems to be quite in line with both the
$20 \%$ reduction target by 2020 as well as the $27 \%$ target (respectively the $30 \%$ target) by 2030 , the energy conversion sector (especially the transition to renewable energy) has contributed a relatively small share, while lower energy demand has been the key determining factor in the period 2000-2014. Our analysis does not distinguish to which extent lower energy demand is caused by higher energy efficiency or by lower demand for energy services (e.g. due to the economic crisis). If the latter is substantial, compliance with the EU energy efficiency targets as they are defined by the EED, which does not exclude the target achievement by reduction of economic activity, will be questionable in the case of economic recovery. Thus, other methods measuring the progress towards target achievement as they are postulated in the Energy Service Directive (ESD) (European Parliament 2006) could be considered to eliminate this issue. A comprehensive harmonised system of evaluation methods for several energy efficiency technologies and measures was proposed by Thomas and Schüle (2009).

From our analyses, we can derive general policy implications for some Member States showing certain apparent developments. Poland, which shows strongly increasing final energy consumption, has not yet exceeded its 2020 target regarding final energy consumption, but the observed trend could be counteracted by the implementation of additional energy efficiency policies. This is applicable for several other Member States, such as Austria, Finland and to a lesser degree Ireland. Among these countries, Austria and Ireland show an increase in GHG emission compared to 2000. In spite of its high share of renewables in electricity generation, Ireland still faces a gap of over $7 \%$ to its 2020 target regarding the share of renewables in total final consumption. This implies the need for stronger policies promoting the use of renewable energy technologies in Ireland.

Monitoring the progress of the European Union and its Member States towards the EU's energy efficiency target is a crucial part of the mandatory process as defined in the Energy Efficiency Directive. Analysing the underlying developments of this progress thoroughly, as done in this paper, offers insights which help to steer and to accelerate the process of target achievement.

\section{Compliance with ethical standards}

Conflict of interest The authors declare that they have no conflict of interest. 


\section{Annex}

Table 1 Results of decomposition on level 1: change of primary energy consumption and explaining factors 2000-2014 (Note: The colours indicate the highest negative value in green to the highest positive value in red by row. Values in million tonnes of oil equivalent)

\begin{tabular}{|c|c|c|c|c|c|c|c|c|c|c|c|c|c|c|c|c|c|c|c|c|c|c|c|c|}
\hline \multirow[b]{2}{*}{ 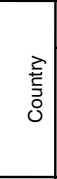 } & \multicolumn{4}{|c|}{ Total change } & \multicolumn{4}{|c|}{$\begin{array}{c}\text { Energy available for final } \\
\text { Consumption }\end{array}$} & \multicolumn{4}{|c|}{ Distribution losses } & \multicolumn{4}{|c|}{$\begin{array}{c}\text { Conversion sector con- } \\
\text { sumption }\end{array}$} & \multicolumn{4}{|c|}{$\begin{array}{c}\text { Structure of conversion } \\
\text { sector }\end{array}$} & \multicolumn{4}{|c|}{$\begin{array}{c}\text { Conversion sector effi- } \\
\text { ciency }\end{array}$} \\
\hline & 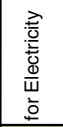 & $\begin{array}{l}\text { đ্ } \\
\stackrel{\Phi}{1} \\
\dot{0}\end{array}$ & 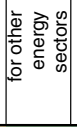 & 要 & 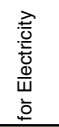 & 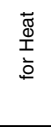 & 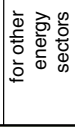 & 푱 & 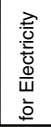 & 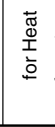 & 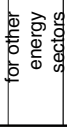 & 퓸 & 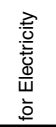 & $\begin{array}{l}\mathbb{\Xi} \\
\stackrel{\mathbb{T}}{T} \\
\vdots \\
\stackrel{0}{0}\end{array}$ & 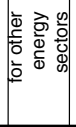 & $\begin{array}{l}\bar{\pi} \\
\text { 으 }\end{array}$ & 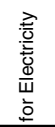 & $\begin{array}{l}\frac{\pi}{\pi} \\
\Phi \\
T \\
\vdots\end{array}$ & 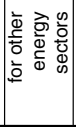 & 呇 & 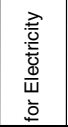 & 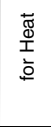 & 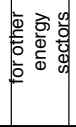 & $\begin{array}{l}\text { त्ञ } \\
\text { 은 }\end{array}$ \\
\hline J28 & -22.67 & 5.50 & -93.28 & 10.45 & -37.60 & -4.90 & -55.79 & -98.28 & -0.57 & -0.07 & -0.85 & -1.50 & -1.64 & -0.21 & -2.43 & -4.28 & 69.60 & .02 & & 1.07 & 52.47 & 1.67 & 3.32 & 47.48 \\
\hline$A^{-}$ & 1.19 & .83 & 1.53 & 3.56 & & 0.22 & 46 & 3.56 & 0.01 & 0.00 & 02 & 0.02 & 01 & 0.00 & 0.04 & 0.06 & 0.43 & .71 & & 0.03 & 0.72 & -0.10 & -0.73 & -0.11 \\
\hline BE & -3.99 & 0.62 & -4.06 & -7.44 & -1.87 & -0.08 & -3.27 & -5.22 & 0.00 & 0.00 & 0.00 & 0.00 & 08 & 0.00 & 0.14 & 0.22 & -0.73 & 0.21 & 12 & -0.41 & -1.47 & 0.49 & -1.06 & -2.03 \\
\hline$B G$ & 0.42 & -0.06 & -0.66 & -0.30 & -0.60 & -0.11 & -0.41 & -1.13 & -0.21 & -0.04 & -0.15 & -0.40 & 0.14 & 0.03 & 0.10 & 0.26 & 2.06 & 0.23 & 1.22 & 1.07 & -0.96 & -0.17 & 1.03 & -0.10 \\
\hline пा & 0.09 & .05 & & -0.10 & & 0.01 & 0.22 & 0.30 & & 0.00 & -0.06 & -0.09 & 06 & -0.01 & -0.17 & -0.23 & 0.34 & -0.04 & & 0.14 & 25 & 01 & 03 & -0.23 \\
\hline $\mathrm{CY}$ & & & & & & & & & & & - & - & & & - & & & & - & & - & - & - & \\
\hline $\mathrm{CZ}$ & 2.12 & 0.31 & -2.24 & -0.42 & -1.31 & -0.37 & -1.52 & -3.20 & 0.03 & 0.01 & 0.04 & 0.08 & 0.03 & 0.01 & 0.04 & 0.08 & 3.75 & -0.23 & -1.59 & 1.93 & -0.39 & 0.27 & 0.80 & 0.68 \\
\hline DK & -1.14 & .38 & 1.25 & -2.78 & -0.38 & -0.35 & 0.91 & -1.64 & 2 & 0. & 5 & 0.08 & 02 & 0. & 0.0 & 0.07 & -0.13 & 0.43 & 23 & 0.07 & 0.67 & -0.50 & -0.1 & -1.36 \\
\hline EE & 0.71 & -0.20 & 1.31 & 1.82 & & 0.21 & 0.74 & 1.61 & -0.09 & -0.03 & -0.11 & -0.23 & 0.02 & 0.0 & 0.0 & 0.04 & 0.29 & 0.35 & 23 & 0.17 & -0.17 & 0.04 & 0. & 0.23 \\
\hline $\mathrm{FI}$ & 48 & 0.77 & 80 & 2.05 & & 0.25 & .86 & 1.79 & 0.04 & 0.0 & 0.06 & 0.12 & 0.07 & 0.02 & 0.0 & 0.17 & 14 & 0.56 & 05 & -0.53 & 0.82 & -0.07 & -0.2 & 0.50 \\
\hline FR & 4.10 & 0.49 & -11.37 & -6.79 & 48 & -0.17 & -5.27 & 10.92 & 0.62 & 0.02 & 0.59 & 1.23 & -2.62 & -0.08 & -2.52 & -5.22 & 12.43 & -0.47 & -4.83 & 7.13 & -0.85 & .18 & 0.67 & 1.00 \\
\hline DE & -10.94 & 5.26 & -19.46 & -25.14 & -7.62 & -0.75 & -11.27 & -19.64 & -0.19 & -0.02 & -0.28 & -0.50 & -0.56 & -0.06 & -0.83 & -1.45 & 18.42 & 4.64 & -11.85 & 11.21 & -20.99 & 1.44 & 4.79 & -14.76 \\
\hline GR & -1.20 & .09 & -2.77 & 3.87 & -1.85 & -0.02 & -2.35 & -4.22 & 0.02 & 0.00 & 0.03 & 0.06 & 0.47 & 0.00 & 0.59 & 1.07 & 0.63 & 0.07 & -0.27 & 0.43 & -0.47 & 0.03 & $\begin{array}{ll}3 & -0.77\end{array}$ & -1.21 \\
\hline 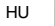 & -0.78 & -0.55 & -1.68 & -3.02 & -0 & -0.09 & .05 & -1.87 & -0.13 & -0.02 & -0.18 & -0.33 & -0.10 & -0.01 & -0.14 & -0.25 & -0.61 & -0.39 & 0.64 & -0.36 & 0.79 & -0.04 & -0.96 & -0.21 \\
\hline IE & -0.53 & 00 & 2 & -0.40 & & 0.00 & 1 & 0.62 & 0.01 & & & 0. & & 0 & -0. & -0.01 & 0.21 & 0.00 & 10 & 0.1 & & 00 & -0 & -1.15 \\
\hline 11 & -8.86 & 7.84 & -21.36 & -22.38 & -6.22 & -0.03 & 11.53 & -17.77 & 0.05 & 0.00 & 0.10 & 0.15 & 10 & 0.00 & 0.29 & 0.45 & 6.62 & 7.77 & -7.99 & 6.39 & -9.46 & 10 & -2.24 & -11.60 \\
\hline LV & - & - & - & - & - & 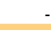 & - & & - & - & - & - & - & $\begin{array}{ll}- \\
-\end{array}$ & 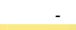 & & - & & - & & & - & 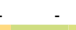 & \\
\hline & -1.68 & 01 & 98 & -0.69 & & 0.28 & 92 & 1.70 & .11 & -0.06 & -0.19 & 36 & 7 & -0.04 & 3 & -0.23 & -1.99 & 0.34 & .05 & -1.27 & -0.02 & 0.16 & -0.67 & -0.53 \\
\hline LU & 0.12 & 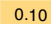 & 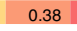 & 0.61 & & 0.0 & 42 & 0.51 & 0.00 & 0. & 1 & 0.01 & & 0. & 1 & 0.01 & 0.56 & 11 & 18 & 0.49 & 53 & -0.02 & 0 & -0.41 \\
\hline . & & & & & & & & & & & & & & & & & & & & & & & & \\
\hline $\mathrm{NL}$ & 1.33 & 92 & .93 & -3.52 & -1.94 & -0.65 & .96 & 55 & 1 & & 3 & 0.05 & & & & 1.1 & 4.01 & 0.70 & 44 & 1.87 & & 32 & & 0.97 \\
\hline $\mathrm{P}$ & 9 & -2 & & & & 15 & & 20 & -0.16 & -0 & -0 & -0.50 & & $-c$ & -1. & -2.32 & 7 & -3. & 18 & -1.47 & 10 & 18 & 9 & -1.21 \\
\hline PI & -0.05 & 0. & & & & -0.05 & 73 & & 0.08 & & & 0.23 & & & & 0.44 & 7 & 0.60 & & 1.08 & & -0.06 & & -1.25 \\
\hline RO & 1.46 & -3.97 & -1.45 & -3.96 & -0 . & -0.34 & -1.52 & -2.59 & -0.17 & -0.08 & -0.35 & -0.60 & -0.38 & -0.18 & -0.8 & -1.36 & 3.42 & -3.23 & 0.36 & 0.55 & -0.68 & -0.13 & & 0.05 \\
\hline SI & 0.38 & -0.03 & 0.00 & 0.34 & 0. & 0.01 & 0.11 & 0.20 & 0.00 & 0.00 & 0.00 & 0.01 & 0. & 0.00 & 0.00 & -0.01 & 0.56 & -0.07 & -0.26 & 0.23 & -0.26 & 0.02 & 0.15 & -0.09 \\
\hline SK & -0.24 & -0.57 & -0.92 & -1.74 & -0.71 & -0.12 & -1.02 & -1.85 & -0.03 & 0.00 & -0.04 & -0.07 & 0.22 & 0.04 & 0.32 & 0.58 & -0.28 & 0.03 & 0.09 & -0.15 & 0.55 & -0.51 & -0.27 & -0.24 \\
\hline $\mathrm{ES}$ & 2. & 0.0 & & & & 0.0 & & -3.00 & 0.38 & 0 & 0.54 & 0.92 & & 0. & 2. & 3.7 & 0 & .00 & -4.37 & 5.12 & -8.05 & 0.00 & 0.04 & -8.00 \\
\hline SE & & 0. & & & & 0.35 & & -3.11 & -0.24 & -0.04 & -0.20 & -0.48 & & 0.0 & 0. & 0.86 & 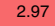 & 0.88 & -2.58 & 1.27 & -0.91 & 0.38 & 1.51 & 0.99 \\
\hline UK & 12.30 & -0.69 & -23.83 & -36.82 & 1.43 & -0.44 & 9.23 & -31.10 & -0.35 & -0.01 & -0.59 & -0.96 & 1.08 & -0.04 & -1.82 & -2.94 & 5.00 & -0.66 & -1.62 & 2.73 & -4.45 & 0.47 & -0.58 & -4.56 \\
\hline
\end{tabular}

Table 2 Results of decomposition on level 2 - change of primary energy consumption due to electricity generation and explaining factors 2000-2014 (Note: The colours indicate the highest negative value in green to the highest positive value in red by row. Values in million tonnes of oil equivalent)

\begin{tabular}{|c|c|c|c|c|c|c|c|c|c|c|c|c|c|c|c|c|c|c|c|c|}
\hline \multicolumn{21}{|c|}{ Level2 } \\
\hline \multirow[t]{2}{*}{ రે } & 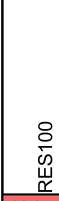 & 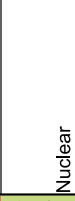 & 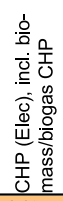 & 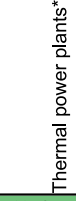 & $\begin{array}{l}\bar{\pi} \\
\stackrel{0}{0} \\
\end{array}$ & $\begin{array}{l}8 \\
\stackrel{0}{0} \\
\overleftrightarrow{山} \\
\end{array}$ & $\begin{array}{l}\frac{\bar{d}}{\mathbb{d}} \\
\frac{\omega}{0} \\
\bar{z} \\
z\end{array}$ & 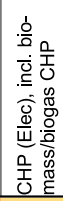 & 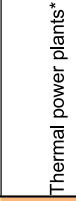 & 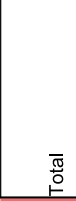 & $\begin{array}{l}8 \\
\frac{0}{\infty} \\
\text { జ }\end{array}$ & 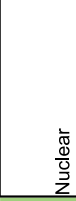 & 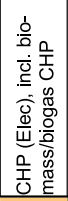 & 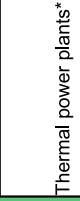 & $\begin{array}{l}\bar{\pi} \\
\text { 음 }\end{array}$ & 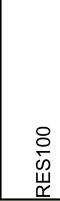 & $\begin{array}{l}\frac{\bar{d}}{0} \\
\frac{d}{0} \\
\frac{\partial}{Z}\end{array}$ & 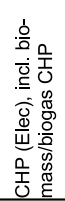 & 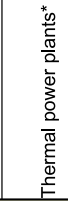 & $\begin{array}{l}\bar{\pi} \\
\stackrel{0}{0}\end{array}$ \\
\hline & \begin{tabular}{|l|}
29.94 \\
\end{tabular} & -17.72 & 9.64 & -44.53 & -22.67 & 2.42 & 11.69 & 3.26 & 12.31 & 29.68 & 27.51 & -29.41 & 8.53 & -48.33 & -41.70 & 0.00 & 0.00 & -2.16 & -8.50 & -10.65 \\
\hline AT & 0.53 & 0.00 & 0.65 & 0.01 & 1.19 & 0.26 & 0.00 & 0.09 & 0.12 & 0.47 & 0.27 & 0.00 & 0.52 & -1.32 & -0.53 & 0.00 & 0.00 & 0.04 & 1.21 & 1.26 \\
\hline $\mathrm{BE}$ & 0.63 & -3.73 & 0.62 & -1.51 & -3.99 & -0.05 & -1.51 & -0.19 & -0.74 & -2.50 & 0.68 & -2.22 & 1.14 & -1.38 & -1.78 & 0.00 & 0.00 & -0.32 & 0.61 & 0.29 \\
\hline BG & 0.41 & -0.60 & 0.42 & 0.18 & 0.42 & 0.06 & 0.65 & 0.10 & 0.55 & 1.37 & 0.35 & -1.25 & 0.30 & -0.09 & -0.69 & 0.00 & 0.00 & 0.01 & -0.28 & -0.27 \\
\hline HR & 0.29 & 0.00 & 0.20 & -0.40 & 0.09 & 0.13 & 0.00 & 0.06 & 0.15 & 0.33 & 0.17 & 0.00 & 0.15 & -0.88 & -0.56 & 0.00 & 0.00 & -0.01 & 0.33 & 0.32 \\
\hline $\mathrm{CY}$ & - & - & - & - & - & - & - & - & - & - & - & - & - & - & - & - & - & - & - & - \\
\hline $\mathrm{CZ}$ & 0.28 & 4.32 & -0.34 & -2.14 & 2.12 & 0.05 & 0.85 & 0.40 & 1.16 & 2.45 & 0.23 & 3.47 & -0.64 & -2.26 & 0.80 & 0.00 & 0.00 & -0.10 & -1.04 & -1.13 \\
\hline DK & 0.81 & 0.00 & -0.72 & -1.23 & -1.14 & -0.08 & 0.00 & -0.25 & -0.12 & -0.45 & 0.89 & 0.00 & -0.16 & -1.52 & -0.80 & 0.00 & 0.00 & -0.31 & 0.41 & 0.10 \\
\hline $\mathrm{EE}$ & 0.05 & 0.00 & 0.09 & 0.57 & 0.71 & 0.00 & 0.00 & 0.09 & 0.77 & 0.87 & 0.05 & 0.00 & -0.01 & -0.11 & -0.07 & 0.00 & 0.00 & 0.00 & -0.09 & -0.09 \\
\hline FI & -0.02 & 0.28 & -0.17 & 0.38 & 0.48 & -0.03 & -0.16 & -0.09 & -0.06 & -0.34 & 0.01 & 0.45 & -0.12 & -0.32 & 0.03 & 0.00 & 0.00 & 0.03 & 0.76 & 0.79 \\
\hline FR & 1.77 & 5.50 & -0.17 & -1.12 & 5.97 & 0.29 & 4.55 & 0.13 & 0.00 & 4.96 & 1.48 & 0.95 & -0.43 & -0.02 & 1.98 & 0.00 & 0.00 & 0.14 & -1.10 & -0.97 \\
\hline $\mathrm{DE}$ & 7.18 & -18.70 & 5.36 & -4.78 & -10.94 & 0.50 & 2.86 & 1.05 & 5.50 & 9.91 & 6.67 & -21.55 & 4.99 & -3.52 & -13.41 & 0.00 & 0.00 & -0.68 & -6.76 & -7.43 \\
\hline GR & 0.65 & 0.00 & 0.13 & -1.98 & -1.20 & -0.04 & 0.00 & -0.02 & -0.66 & -0.72 & 0.69 & 0.00 & 0.16 & -2.11 & -1.26 & 0.00 & 0.00 & 0.00 & 0.79 & 0.78 \\
\hline HU & 0.07 & 0.38 & -1.19 & -0.04 & -0.78 & -0.01 & -0.69 & -0.25 & -0.60 & -1.55 & 0.08 & 1.07 & -0.90 & -0.46 & -0.20 & 0.00 & 0.00 & -0.04 & 1.02 & 0.97 \\
\hline IE & 0.41 & 0.00 & 0.25 & -1.18 & -0.53 & 0.03 & 0.00 & 0.02 & 0.38 & 0.42 & 0.38 & 0.00 & 0.26 & -1.16 & -0.51 & 0.00 & 0.00 & -0.03 & -0.40 & -0.43 \\
\hline IT & 3.98 & 0.00 & 2.09 & -14.92 & -8.86 & 0.07 & 0.00 & 0.07 & 0.46 & 0.60 & 3.91 & 0.00 & 2.55 & -13.34 & -6.89 & 0.00 & 0.00 & -0.53 & -2.04 & -2.57 \\
\hline LV & - & - & - & - & - & - & - & - & - & - & - & - & - & - & - & - & - & - & - & - \\
\hline LT & 0.10 & -2.17 & 0.13 & 0.26 & -1.68 & -0.09 & -0.06 & 0.00 & -0.58 & -0.73 & 0.19 & -2.05 & 0.14 & 0.09 & -1.63 & 0.00 & 0.00 & 0.00 & 0.75 & 0.68 \\
\hline LU & 0.04 & 0.00 & 0.00 & 0.09 & 0.12 & 0.09 & 0.00 & 0.05 & 0.51 & 0.65 & -0.05 & 0.00 & -0.02 & 1.11 & 1.05 & 0.00 & 0.00 & -0.03 & -1.54 & -1.57 \\
\hline MT & - & - & - & - & - & - & - & - & - & - & - & - & - & - & 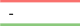 & - & - & - & - & - \\
\hline NL & 0.49 & 0.04 & 0.24 & 0.56 & 1.33 & 0.04 & 0.15 & 0.77 & 1.41 & 2.36 & 0.45 & -0.11 & -0.50 & -0.28 & -0.43 & 0.00 & 0.00 & -0.03 & -0.57 & -0.60 \\
\hline PL & 0.54 & 0.00 & 0.43 & 1.12 & 2.09 & 0.05 & 0.00 & 0.43 & 2.00 & 2.48 & 0.49 & 0.00 & 0.11 & -1.14 & -0.55 & 0.00 & 0.00 & -0.10 & 0.26 & 0.15 \\
\hline PT & 1.33 & 0.00 & 0.27 & -1.67 & -0.07 & 0.26 & 0.00 & 0.13 & 0.80 & 1.20 & 1.07 & 0.00 & 0.26 & -3.27 & -1.94 & 0.00 & 0.00 & -0.13 & 0.79 & 0.66 \\
\hline RO & \begin{tabular}{|l}
0.47 \\
\end{tabular} & 1.59 & -1.11 & 0.32 & 1.27 & 0.19 & 0.26 & 0.25 & 0.41 & 1.12 & 0.28 & 1.33 & -1.22 & 0.22 & 0.61 & 0.00 & 0.00 & -0.15 & -0.31 & -0.46 \\
\hline SI & 0.11 & 0.14 & 0.13 & 0.00 & 0.38 & 0.06 & 0.22 & 0.15 & 0.01 & 0.43 & 0.05 & -0.08 & -0.01 & -0.01 & -0.05 & 0.00 & 0.00 & -0.01 & 0.00 & -0.01 \\
\hline SK & 0.07 & -3.13 & 0.39 & -0.35 & -3.03 & -0.04 & -0.18 & -0.10 & -0.02 & -0.34 & 0.10 & -2.95 & 1.32 & -0.35 & -1.89 & 0.00 & 0.00 & -0.82 & 0.03 & -0.80 \\
\hline ES & 6.11 & -1.41 & 0.91 & -4.18 & 1.44 & 1.32 & 3.58 & 0.87 & 5.00 & 10.78 & 4.79 & -4.99 & -0.55 & -7.00 & -7.76 & 0.00 & 0.00 & 0.59 & -2.17 & -1.58 \\
\hline SE & -0.66 & 2.36 & 0.78 & -0.48 & 2.00 & 0.34 & 0.84 & 0.06 & 0.00 & 1.25 & -1.00 & 1.51 & 0.63 & -0.03 & 1.10 & 0.00 & 0.00 & 0.09 & -0.45 & -0.35 \\
\hline UK & 2.52 & -3.73 & -0.17 & -5.16 & -6.54 & -0.08 & -0.97 & -0.17 & -2.49 & -3.72 & 2.61 & -2.75 & -0.83 & -3.01 & -3.99 & 0.00 & 0.00 & 0.83 & 0.34 & 1.17 \\
\hline
\end{tabular}




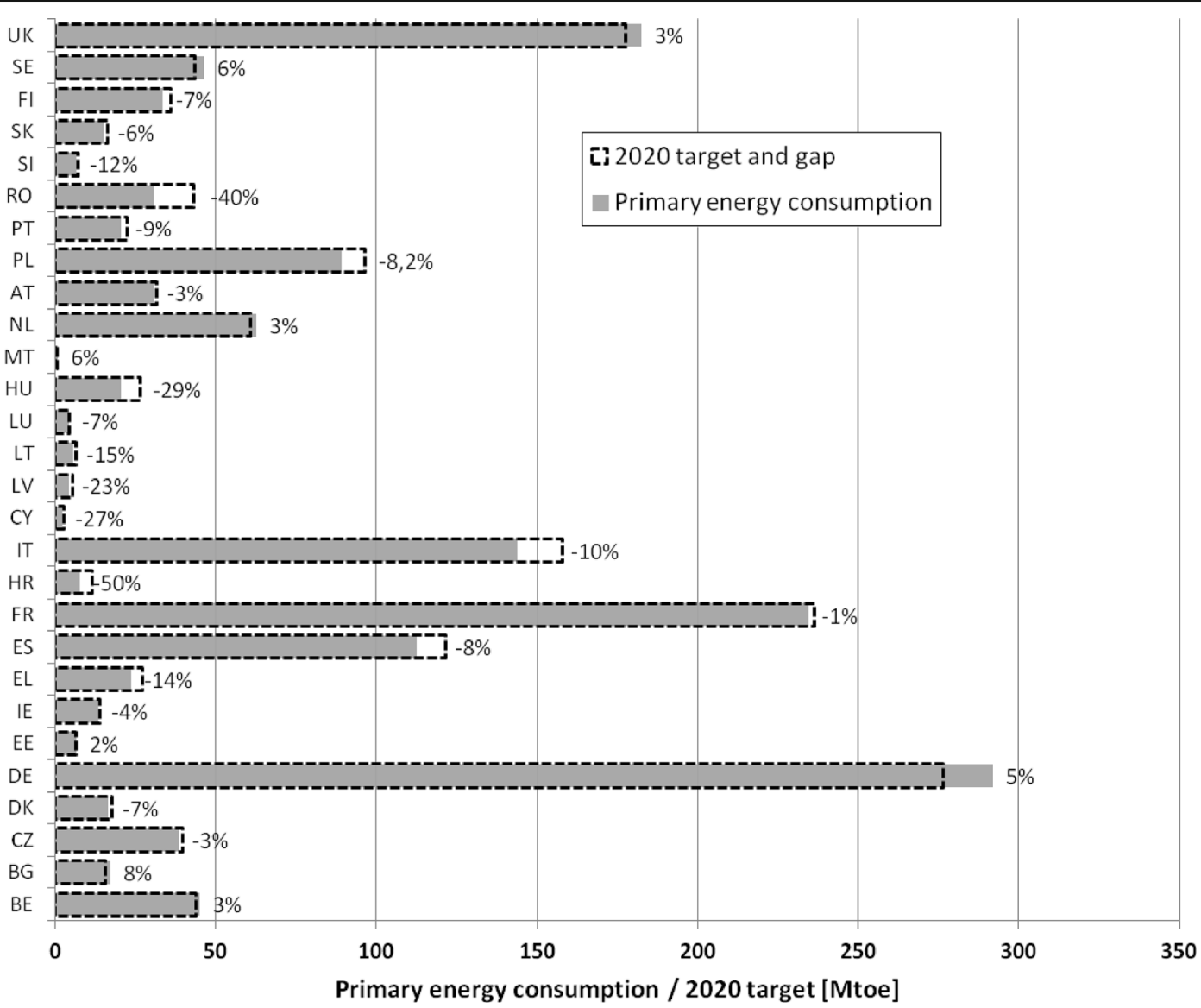

Fig. 12 Primary energy consumption of the MS in 2014, primary energy target for 2020 and gap to the target in percent

Open Access This article is distributed under the terms of the Creative Commons Attribution 4.0 International License (http:// creativecommons.org/licenses/by/4.0/), which permits unrestricted use, distribution, and reproduction in any medium, provided you give appropriate credit to the original author(s) and the source, provide a link to the Creative Commons license, and indicate if changes were made.

\section{References}

AGEB (2015). Ausgewählte Effizienzindikatoren zur Energiebilanz Deutschland. AG Energiebilanzen e.V. Available online at www.ag-energiebilanzen.de, checked on 9/15/2016.

AGEB (2016). Energieverbrauch in Deutschland 2015. With assistance of Hans-Joachim Ziesing. Edited by AG Energiebilanzen e.V. Berlin. Available online at http://www.ag-energiebilan-zen. $\mathrm{de} / \mathrm{index} \cdot \mathrm{php}$ ?article_id $=29 \&$ file $\mathrm{Name}=\mathrm{ageb}$ jahresbericht2015_20160317_final.pdf, checked on 9/15/2016.

Agnolucci, P., Ekins, P., Iacopini, G., Anderson, K., Bows, A., Mander, S., \& Shackley, S. (2009). Different scenarios for achieving radical reduction in carbon emissions. A decomposition analysis. Ecological Economics, 68(6), 1652-1666. doi:10.1016/j.ecolecon.2007.09.005.
Ang, B. W. (2004). Decomposition analysis for policymaking in energy: which is the pre-ferred method? Energy Policy, 32(9), 1131-1139. doi:10.1016/s0301-4215(03)00076-4.

Ang, B. W. (2005). The LMDI approach to decomposition analysis: a practical guide. Energy Policy, 33(7), 867-871. doi:10.1016/j.enpol.2003.10.010.

Ang, B. W. (2015). LMDI decomposition approach: a guide for implementation. Energy Policy, 86, 233-238. doi:10.1016/j. enpol.2015.07.007.

Ang, B. W., \& Choi, K. (1997). Decomposition of aggregate energy and gas emission intensities for industry: a refined Divisia index method. The Energy Journal, 18(3), 59-73 Available online at http://www.jstor.org/stable/41322738.

Ang, B. W., \& Liu, F. L. (2001). A new energy decomposition method: perfect in decom-position and consistent in aggregation. Energy, 26(6), 537-548. doi:10.1016/S0360-5442(01)00022-6.

Ang, B. W., \& Liu, N. (2007). Handling zero values in the logarithmic mean Divisia index decomposition approach. Energy Policy, 35(1), 238-246. doi:10.1016/j.enpol.2005.11.001.

Ang, B. W., \& Zhang, F. Q. (2000). A survey of index decomposition analysis in energy and environmental studies. Energy, 25(12), 1149-1176. doi:10.1016/S0360-5442(00)00039-6.

Ang, B. W., Huang, H. C., \& Mu, A. R. (2009). Properties and linkages of some index decomposition analysis methods. 
Energy Policy, 37(11), 4624-4632. doi:10.1016/j. enpol.2009.06.017.

BMWi (2014). The energy of the future. First "Energy Transition" Progress Report-Summary. BMWi. Available online at http://www.bmwi.de/English/Redaktion/Pdf/fortschrittsberichtkurzfassung-en,property=pdf,bereich=bmwi2012, , prache= en,rwb=true.pdf, checked on 9/15/2016.

Capros, P., Mantzos, L., Papandreou, V., \& Tasios, N. (2008). European energy and transport trends to 2030. Update 2007. Luxembourg: EUR-OP.

Capros, P., de Vita, A., Tasios, N., Evangelopoulou, S., Forsell, N., Fragiadakis, K., et al. (2016). EU reference scenario 2016. Energy, transport and GHG emissions: trends to 2050. Luxembourg: Publications Office.

Colinet Carmona, M. J., \& Román Collado, R. (2016). LMDI decomposition analysis of energy consumption in Andalusia (Spain) during 2003-2012. The energy efficiency policy implications. Energy Efficiency, 9(3), 807-823. doi:10.1007/s12053-015-9402-y.

Edenhofer, O., PichsMadruga, R., \& Sokona, Y. (2012). Renewable energy sources and climate change mitigation. Special report of the Intergovernmental Panel on Climate Change. New York: Cambridge University Press.

European Commission (2008). Commission decision establishing detailed guidelines for the implementation and application of Annex II to Directive 2004/8/EC of the European Parliament and of the Council. Available online at http://eur-lex.europa. eu/legalcontent/EN/ALL/?uri=CELEX:32008D0952, checked on 1/30/2017.

European Commission (2009). Directive 2009/28/EC of the European Parliament and of the Council on the promotion of the use of energy from renewable sources and amending and subsequently repealing Directives 2001/77/EC and 2003/30/EC (Official Journal of the European Union L140/ 16 from 5 June 2009). Available online at http://eur-lex. europa.eu/legal-content/EN/TXT/?uri=CELEX:32009 L0028, checked on 9/15/2016.

European Commission (2012). Directive 2012/27/EU of the European Parliament and of the Council of 25 October 2012 on energy efficiency, amending Directives 2009/125/ EC and 2010/30/EU and repealing directives 2004/8/EC and 2006/32/EC (Official Journal of the European Union L315/1 from 11 November 2012). Available online at http://eur-lex. europa.eu/legal-content/EN/TXT/PDF/?uri=CELEX:32012 L0027, checked on 9/15/2016.

European Commission (2013). Council Directive 2013/12/EU of 13 May 2013 adapting Directive 2012/27/EU of the European Parliament and of the Council on energy efficiency, by reason of the accession of the Republic of Croatia (Official Journal of the European Union L148/28 from 28 May 2013). Available online at http://eur-lex.europa.eu/legalcontent/EN/TXT/PDF/?uri=CELEX:32013L0012, checked on $9 / 15 / 2016$.

European Commission (2014). Communication from the Commission to the European Parliament and the Council. Energy Efficiency and its contribution to energy security and the 2030Framework for climate and energy policy. Available online at https://ec.europa. eu/energy/sites/ener/files/documents/2014_energy_efficiency_ communication.pdf, checked on 9/15/2016.

European Commission (2015a). Energy Statistics of the European Union: Concepts and Definitions on all Flows ("Aggregates") and Products used in the Energy Statistics on Quantities. Available online at http://ec.europa. eu/eurostat/documents/38154/4956233/RAMON-CODEDENERGY-20150212.pdf, checked on 9/15/2016.

European Commission (2015b). Evolution of indicative national energy efficiency target for 2020. Available online at http://ec.europa.eu/energy/sites/ener/files/documents/Article 3 EED_Indicative national energy efficiency targets 2020 (October 2015).pdf, checked on 9/15/2016.

European Commission (2016a). Proposal for a Regulation of the European Parliament and of the Council on binding annual greenhouse gas emission reductions by Member States from 2021 to 2030 for a resilient Energy Union and to meet commitments under the Paris Agreement and amending Regulation No 525/2013 of the European Parliament and the Council on a mechanism for monitoring and reporting greenhouse gas emissions and other information relevant to climate change. Available online at https:/ec.europa. eu/transparency/regdoc/rep/1/2016/EN/1-2016-482-EN-F11.PDF, checked on $9 / 15 / 2016$.

European Commission (2016b). Proposal for a directive of the European Parliament and of the Council amending Directive 2012/27/EU on energy efficiency. Available online at http://ec.europa.eu/energy/sites/ener/files/documents/1_en act_part1_v16.pdf.

European Council (2009). 11 and 12 December 2008, Presidency Conclusion. 17271/1/08 Rev 1. Brussels. Available online at http://www.consilium.europa.eu/uedocs/cms data/docs/pressdata/en/ec/104692.pdf, checked on 9/15/2016.

European Council (2014). European Council 23 and 24 October 2014. EUCO 169/14, CO EUR 13, Concl 5. Brussels. Available online at http://www.consilium.europa. eu/uedocs/cms_data/docs/pressdata/en/ec/145397.pdf, checked on 9/15/2016.

European Parliament (2006). Directive 2006/32/EC of the European Parliament and of the Council of 5 April 2006 on energy end-use efficiency and energy services and repealing Council Directive 93/76/EEC. Available online at http://eurlex.europa.eu/legal-content/EN/TXT/?uri=celex:32006 L0032, checked on 12/30/2016.

European Parliament (2009). Decision No 406/2009/EC of the European Parliament and the Council of 23 April 2009 on the effort of Member States to reduce their green-house gas emissions to meet the Community's greenhouse gas emission reduction commitments up to 2020. Available online at http://eur-lex.europa.eu/LexUriServ/LexUriServ.do?uri= OJ:L:2009:140:0136:0148:EN:PDF, checked on 9/15/2016.

Eurostat (2015a). Nuclear Energy Annual Questionnaire 2014 and Historical Revisions. Eurostat. Available online at http://ec. europa.eu/eurostat/documents/38154/6935814/AQ-2014NUCLEAR-instructions.pdf, checked on 9/15/2016.

Eurostat (2015b). Share of energy from renewable sources. Available online at http://ec.europa.eu/eurostat/tgm/table.do?tab= table\&language $=$ en $\&$ pcode $=\mathrm{t} 2020 \_31$, checked on 9/15/2016.

Eurostat (2016a). Energy from renewable sources. Available online at http://ec.europa.eu/eurostat/statistics-explained/index. php/Energy_from_renewable_sources, checked on 9/15/2016.

Eurostat (2016b). Final energy consumption by sector. Available online at http://ec.europa.eu/eurostat/tgm/table.do?tab= table\&language=en\&pcode=tsdpc320, checked on 9/15/2016.

Fernández González, P., Landajo, M., \& Presno, M. J. (2013). The Divisia real energy intensity indices. Evolution and 
attribution of percent changes in 20 European countries from 1995 to 2010. Energy, 58, 340-349. doi:10.1016/j. energy.2013.06.013.

Fraunhofer-ISI: Study evaluating the current energy efficiency policy framework in the EU and providing orientation on policy options for realising the cost-effective energy efficiency/saving potential until 2020 and beyond. With assistance of Sibylle Braungardt, Wolfgang Eichhammer, Rainer Elsland, Tobias Fleiter, Marian Klobasa, Michael Krail et al. (2014). Fraunhofer ISI. Karlsruhe/Vienna/Rome. Available online at https://ec.europa . eu/energy/sites/ener/files/documents/2014_report_20202030_eu_policy_framework.pdf, checked on 9/15/2016.

Gardner, E. S. (2006). Exponential smoothing. The state of the art-part II. International Journal of Forecasting, 22(4), 637-666. doi:10.1016/j.ijforecast.2006.03.005.

ICF (2016). Decomposition analysis of the changes in GHG emissions in the EU and Member States. With assistance of Jerome Kisielewicz, Martine Sobey, Yann Verstraeten, Angelica Marino, Lucia Lavric, Sebastian Voigt, Sascha Rexhäuser, Benjamin Johannes Lutz, Bernd Gugele, Filip Jirous, Jurga Tallat-Kelpsaite. Available online at https://ec.europa. $\mathrm{eu} / \mathrm{clima} /$ sites/clima/files/strategies/progress/docs/dca_report en.pdf, checked on 12/13/2016.

IEA (2008). Worldwide trends in energy use and efficiency. Edited by International Energy Agency. OECD. Paris.
IEA (2012). World Energy Outlook 2012. Paris, France: International Energy Agency (World energy outlook special report).

IEA (2016). World Energy Balances 2016. Database Documentation. Available online at http://wds.iea.org/wds/pdf/WORLDBAL Documentation.pdf, checked on 9/15/2016.

Moutinho, V., Madaleno, M., \& Silva, P. M. (2016). Which factors drive $\mathrm{CO} 2$ emissions in EU-15? Decomposition and innovative accounting. Energy Efficiency, 9(5), 1087-1113. doi:10.1007/s12053-015-9411-x.

ODYSSEE-MURE (2015). Energy indicators in Europe - decomposition facility. Avail-able online at http://www.indicators. odyssee-mure.eu/decomposition.html, checked on 9/15/2016.

Smit, T. A. B., Hu, J., \& Harmsen, R. (2014). Unravelling projected energy savings in 2020 of EU Member States using decomposition analyses. Energy Policy, 74, 271-285. doi:10.1016/j.enpol.2014.08.030.

Thomas, S., \& Schüle, R. (2009). Measuring and reporting energy savings for the Energy Services Directive. How it can be done; results and recommendations from the EMEEES project. Wuppertal.

Wood, R., \& Lenzen, M. (2006). Zero-value problems of the logarithmic mean divisia index decomposition method. Energy Policy, 34(12), 1326-1331. doi:10.1016/j. enpol.2004.11.010. 